\title{
Plant Non-Coding RNAs: Origin, Biogenesis, Mode of Action and Their Roles in Abiotic Stress
}

\author{
Joram Kiriga Waititu ${ }^{1}$, Chunyi Zhang ${ }^{1}$, Jun Liu ${ }^{2}$ iD and Huan Wang ${ }^{1, *(\mathbb{D})}$ \\ 1 Biotechnology Research Institute, Chinese Academy of Agricultural Sciences, Beijing 100081, China; \\ joram.kiriga@gmail.com (J.K.W.); zhangchunyi@caas.cn (C.Z.) \\ 2 National Key Facility for Crop Resources and Genetic Improvement, Institute of Crop Science, \\ Chinese Academy of Agricultural Sciences, Beijing 100081, China; liujun@caas.cn \\ * Correspondence: wanghuan@caas.cn
}

Received: 13 October 2020; Accepted: 4 November 2020; Published: 9 November 2020

\begin{abstract}
As sessile species, plants have to deal with the rapidly changing environment. In response to these environmental conditions, plants employ a plethora of response mechanisms that provide broad phenotypic plasticity to allow the fine-tuning of the external cues related reactions. Molecular biology has been transformed by the major breakthroughs in high-throughput transcriptome sequencing and expression analysis using next-generation sequencing (NGS) technologies. These innovations have provided substantial progress in the identification of genomic regions as well as underlying basis influencing transcriptional and post-transcriptional regulation of abiotic stress response. Non-coding RNAs (ncRNAs), particularly microRNAs (miRNAs), short interfering RNAs (siRNAs), and long non-coding RNAs (lncRNAs), have emerged as essential regulators of plants abiotic stress response. However, shared traits in the biogenesis of ncRNAs and the coordinated cross-talk among ncRNAs mechanisms contribute to the complexity of these molecules and might play an essential part in regulating stress responses. Herein, we highlight the current knowledge of plant microRNAs, siRNAs, and lncRNAs, focusing on their origin, biogenesis, modes of action, and fundamental roles in plant response to abiotic stresses.
\end{abstract}

Keywords: non-coding RNA; long non-coding RNA; abiotic stress; transcriptional; biogenesis

\section{Introduction}

Plants are sessile species that cannot evade stress but require mechanisms of avoidance and/or tolerance for survival when exposed to ever-changing environmental conditions. Abiotic stresses including cold, heat, hypoxia, drought, nutrient deficiency and salinity affect plant growth and productivity, resulting in substantial loss of yields [1]. Also, the ever-increasing global population, decreasing arable land due to rapid urbanization, significant changes in soil quality and global warming are all projected to exacerbate food security issues further [2].

Non-coding RNAs (ncRNAs) have risen dramatically in recent years as essential bioactive molecules contributing to genomic and phenotypic diversities. While up to $90 \%$ of the eukaryotic genome is transcribed into RNA, only about $2 \%$ of transcribed RNAs generate protein products [3,4]. The remaining transcriptome comprises ncRNAs transcripts, which were previously considered transcriptional noise owing to the absence of protein-coding ability and poorly conserved sequences [3,5]. However, high-throughput sequencing analysis and experimental validation have confirmed the involvement of ncRNAs in a myriad of distinct gene regulatory levels, including epigenetic, transcriptional, and post-transcriptional [6-8]. Thus, the advancement of effective next-generation sequencing (NGS) technologies $[9,10]$ in conjunction with homology-based and/or experimental approaches has been vital to discovering ncRNAs in plants. 
Since their initial discovery, ncRNAs have been categorized into several distinct classes based on their origin, biogenesis, and mechanism of action. Housekeeping and regulatory ncRNAs are the major groups of ncRNA transcripts. The housekeeping ncRNAs primarily deals with cellular and ribosomal functions. They include transfer RNAs (tRNAs), small nuclear RNAs (snRNAs), ribosomal RNAs (rRNAs), and small nucleolar RNAs (snoRNAs) (Figure 1). On the other hand, the regulatory ncRNAs consist of microRNAs (miRNAs), short interfering RNAs (siRNAs), piwi-interacting RNAs (piRNAs), and long non-coding RNAs (lncRNAs) [11], (Figure 1). These regulatory ncRNAs are transcribed from DNA but lack the ability to translate into proteins. [7,12]. Nevertheless, they perform a myriad of vital functions in plant growth, development, and abiotic stress responses at transcription and post-transcription levels [13].

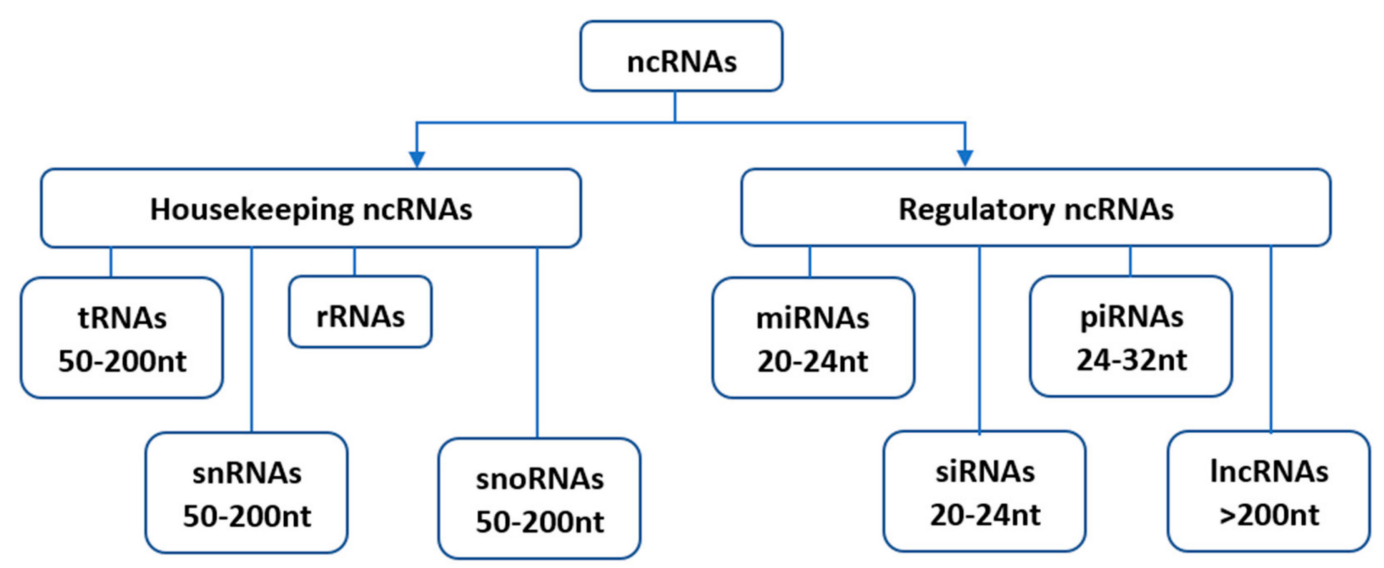

Figure 1. Classification of non-coding RNAs (ncRNAs). Housekeeping ncRNAs include; tRNAstransfer RNAs, snRNAs-small nuclear RNAs, rRNAs-ribosomal RNAs, snoRNAs-small nucleolar RNAs. The regulatory ncRNAs consist of miRNAs-microRNAs, siRNAs-short interfering RNAs, piRNAs-piwi-interacting RNAs, and lncRNAs-long non-coding RNAs.

Over the past decades, fundamental advancement has been achieved in unfolding the dynamic and complicated mechanisms underlying plant response to environmental stresses. Considerable effort has been channelled towards identifying stress-responsive genes as well as their respective protein interaction networks. This led to the observation that plant stress response depends on the accurate expression and regulation of genes achieved via multiple mechanisms at various levels like transcriptional and post-transcriptional regulations [14,15]. However, despite substantial scientific research that have extensively focused on the regulatory mechanisms of coding proteins, recent findings have pinpointed the essential functions of ncRNAs in controlling transcriptional and post-transcriptional gene expression levels during plant developmental and environmental stress responses [16]. In this review, we summarize the current tremendous progress on ncRNAs molecules from miRNAs, siRNAs to lncRNAs with an extensive emphasis on their origin, biogenesis, modes of action, and diverse roles orchestrating plant abiotic stress responses.

\section{Origin and Biogenesis of Non-Coding RNAs}

ncRNAs are diverse in both their origin and functions [17]. Duplication, evolution from existing transposable elements (TEs), random hairpin structures, pseudogenization of protein-coding sequences, replication of RNA viruses, and double-stranded RNAs (dsRNAs) from heterochromatin regions, and DNA repeats [18-21] are the leading theories for the origin of various ncRNAs such as miRNAs, siRNAs, piRNAs, and lncRNAs.

MicroRNAs are small but fundamental molecules which are predominantly 20-22 nt in length [22]. They are synthesized from miRNA genes (MIR genes), which are processed by RNA polymerase II (RNA pol II), RNase III Dicer-like protein 1 (DCL1) [23-25] (Figure 2). HASTY (HST) transports the resulting miRNA-miRNA* duplex to the cytoplasm where it is integrated into the RNA-induced 
silencing complex (RISC) containing ARGONAUTE 1 (AGO1) proteins that control gene silencing by mRNA cleavage and translational repression [26-28], (Figure 2).

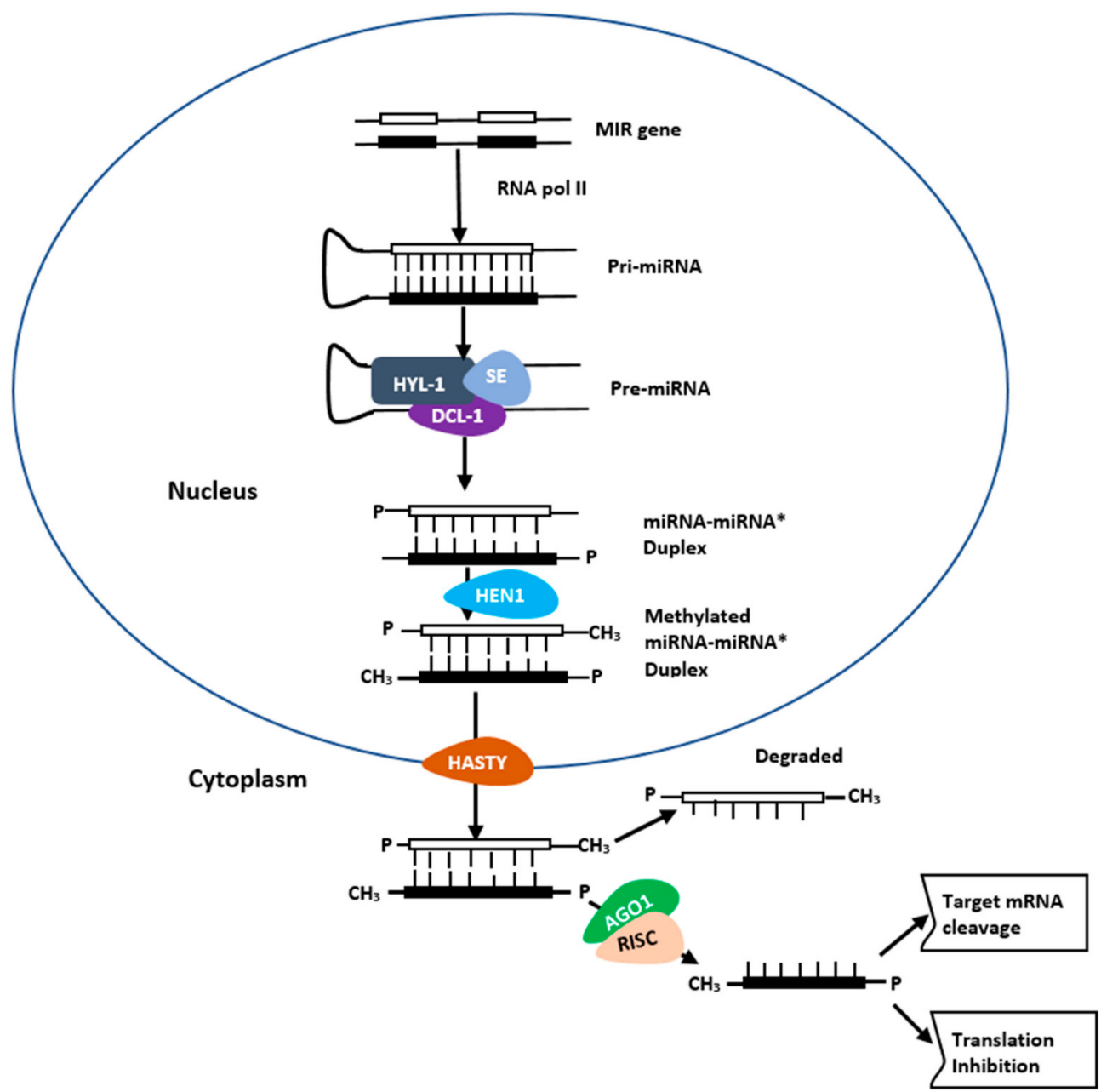

Figure 2. Biogenesis of plant miRNAs. In the nucleus, MIR genes are processed to miRNA/miRNA* duplexes through the action of Pol II, DCL1, SE, HYL1, HEN1, and HASTY. In the cytoplasm, the duplex is incorporated with RISC-AGO complex to which guides it towards the target, resulting in suppression of the translation and cleavage of mRNAs.

The siRNAs are grouped into trans-acting siRNAs (tasiRNA), heterochromatic siRNAs (hc-siRNA), and natural antisense siRNAs (nat-siRNAs) depending on the mode of action as well as biogenesis. tasiRNAs have a regulatory mechanism similar to miRNAs, and they act in cis and operate at loci independent from their biogenesis site. At the same time, hc-siRNA works effectively in cis within their source or homologous regions as their origins align with their targets [29]. However, nat-siRNAs are categorized into cis-nat-siRNAs and trans-nat-siRNAs. The generation of the former involves transcription of two RNAs from opposite strands of the same loci. Simultaneously, the latter involves RNA transcripts hailing from multiple loci [30]. The siRNAs biogenesis involves dsRNAs, DCL enzymes activities, and RISC containing AGO protein that controls target regulation at post-transcription or transcriptional level [31] (Figure 3). Biogenesis of ta-siRNA is dependent on SUPPRESSOR OF GENE SILENCING3 (SGS3), RNA-dependent RNA polymerases 6 (RDR6), and DCL4 [32,33] while that of nat-siRNAs depends on SGS3, RDR6, DCL1, DCL2, and a plant-specific RNA polymerase, NRPD1A [34]. Similarly, hc-siRNAs are generated by Pol IV, DCL3, RDR2, 5S rRNA genes, and NRPD1A [35,36]. 


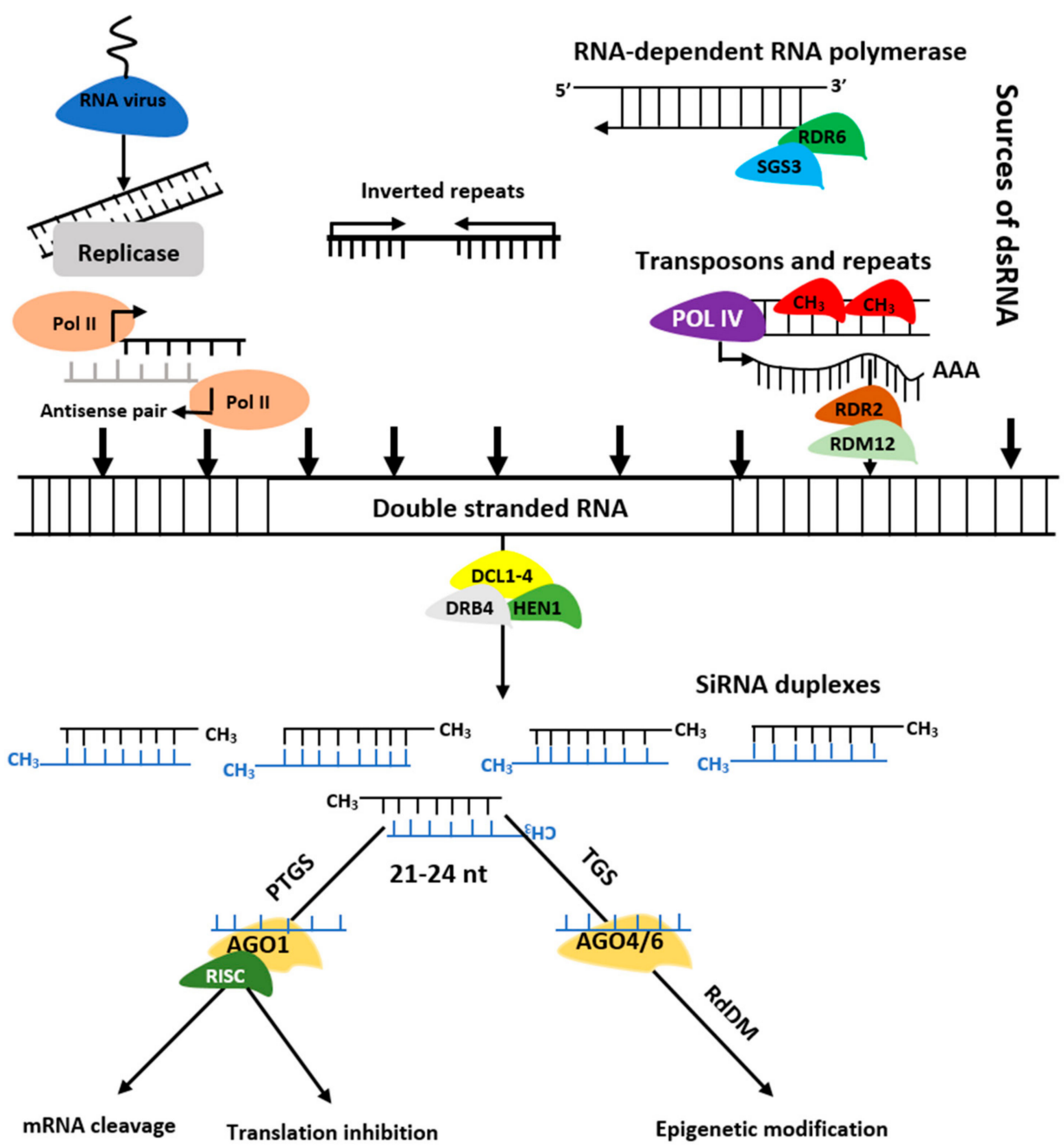

Figure 3. Biogenesis of siRNAs. The double stranded RNA (dsRNAs) is transformed into siRNAs by DCL, HEN1, and DRB. The RISC-AGO complex then guides the selected strands of siRNA duplexes to post transcription gene silencing (PTGS) or transcription gene silencing (TGS).

Long non-coding RNAs are transcripts that exceed more than 200 base pair (bp) in length and cannot be translated into protein [37]. They are classified into cis-natural antisense (cis-NATs), trans-natural antisense transcripts (trans-NATs), and pseudogenes [38], sense or antisense (strand of origin) [39], divergent, or convergent (orientation of transcription), and as intronic or intergenic (location) [40] (Figure 4). They are transcribed by RNA pol II, III, IV, and V and control target regulation via multiple ways, including chromatin remodeling, transcriptional repression, mimicry, RNA splicing and transcriptional enhancer (Figure 4). 


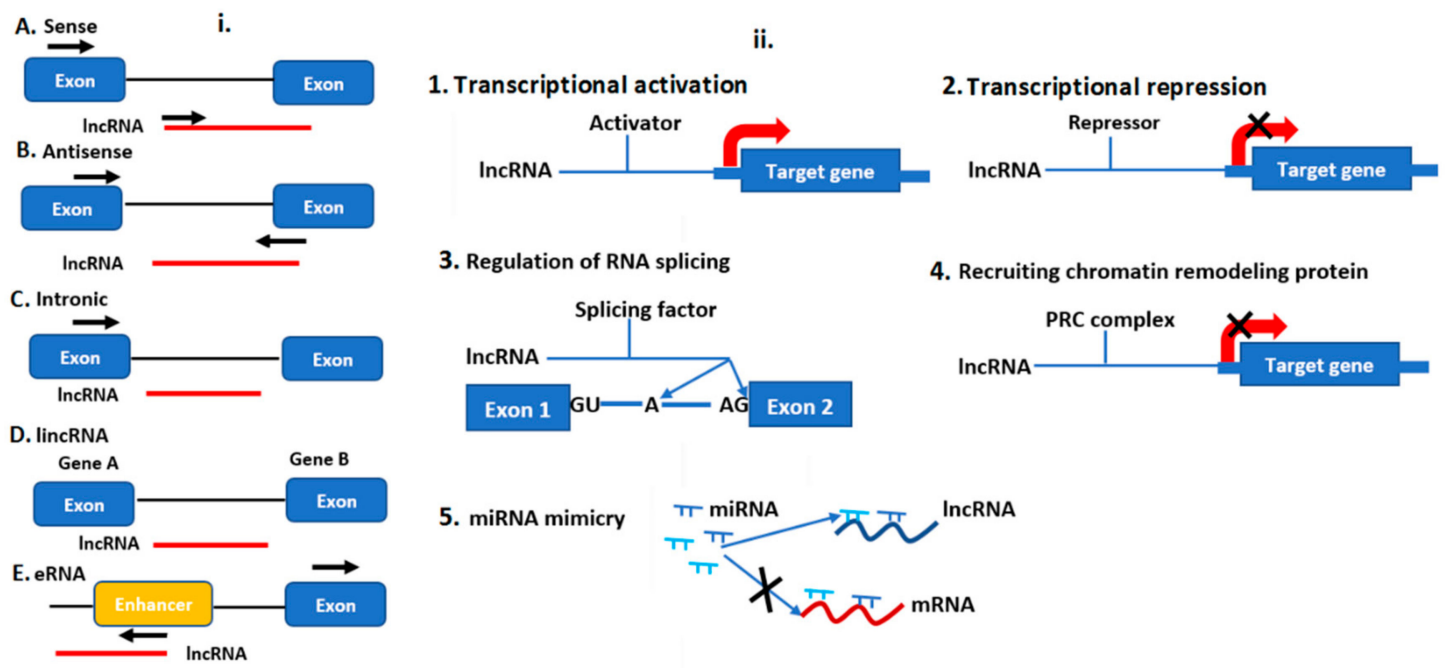

Figure 4. The biogenesis of long-non-coding RNAs (lncRNAs) and their gene regulation mechanisms in plants. (i) The transcripts of lncRNA (red box) are classified on the basis of their genomic location and in relation to the nearest gene (blue box): (A) sense lncRNAs are transcribed on the same strand as an exon; (B) antisense lncRNAs are transcribed on the opposite strand of an exon; (C) intronic lncRNAs are transcribed on the intron; (D) intergenic lncRNAs are located between two distinct genes; (E) enhancer lncRNAs emerge from an enhancer region of protein-coding genes. (ii) The gene regulation pathways induced in plants by lncRNAs. LncRNAs regulate gene expression either by: (1) interacting with transcriptional activator leading to gene activation; (2) interacting with transcriptional repressor thereby suppressing transcription; (3) controlling RNA splicing by interacting with splicing factor or binding premRNA splicing junction; (4) recruiting chromatin remodeling complex such as PRC to regulate gene expression in the promoter region; (5) LncRNA mimics miRNAs by occupying their target sites on the mRNA.

\section{Impact of Non-Coding RNAs on Plant Gene Regulation}

sRNAs such as miRNAs and siRNAs regulate gene expression through a multitude of methods, including (1) cleavage of target mRNA, (2) translational repression, and (3) transcriptional silencing [38,41-43]. Similarly, lncRNAs control gene expression through the hijacking of protein and miRNAs, regulating mRNA stability and translation, and changing chromatin status [44].

\subsection{Cleavage of Target Transcripts by miRNAs and siRNAs}

The sequence-specific cleavage silencing mechanism depends on the binding of the miRNAs and/or siRNAs to the complementary sites in target mRNA molecules [41,45]. For miRNAs, the MIR genes are processed by DCL1, HYL1 and SE complex [20,24,25] into mature miRNA-miRNA* duplex and transported by HASTY protein to the cytoplasm where it is integrated with RISC containing AGO1. The RISC-AGO1 complex binds to the complementary sites of sense sequence on its targeted RNA transcript and degrade it. In contrast, the antisense strand of miRNAs remains in the RISC [46]. In siRNAs, one strand which is integrated with RISC-AGO1 or AGO7 complex is guided to cleave the transcripts of the target gene at 10-11 nt upstream of the $5^{\prime}$ end of the antisense strand [47]. The EXONUCLEASE 4 (XRN4) enzyme then degrade both the $3^{\prime}$ and $5^{\prime}$ cleaved fragments $[48,49]$. Recent studies have reported the RNA binding and target slicer activities of AGO2, AGO4, and AGO10 in plants, indicating the complexity of the sRNA-induced gene silencing mechanism [50,51].

\section{2. miRNAs and siRNAs Induced Translational Inhibition of Target Genes}

In plants, AGO1 and AGO10 stimulate translational inhibition mechanism [52,53] by imperfectly pairing sRNAs with the target mRNA [45,54]. However, the inhibition rate is extremely dependent on the number of miRNA binding sites $[55,56]$. The RISC-AGO1 complex suppresses translation by 
binding to the $5^{\prime}$ untranslated region (UTR) or open reading frame (ORF) of the target gene, thereby restricting ribosome recruitment or movement [57]. This translation inhibition process is regulated by other factors such as ALTERED MERISTEM PROGRAM 1 (AMP1), VARICOSE (VCS), GW-repeat protein, and microtubule enzyme KATANIN (KTN1) [58,59]. Despite the involvement of both AGO1 and AGO10, the specific function of each AGO gene in this inhibition process is still not clear $[58,59]$. Further research is still needed to fully understand the underlying mechanism of sRNAs mediated translation repression and how the repressed target mRNAs escape endonucleolytic cleavage.

\section{3. miRNA and siRNA-Directed DNA Methylation}

The DCL family has multiple copies in Arabidopsis, which contribute to the biogenesis of divergent lengths of sRNA. DCL1 is involved in the conversion of partially paired dsRNA precursors into 21-nt mature miRNAs [60]. On the other hand, DCL2 and DCL44 initiate the generation of 20-22nt siRNAs from perfect complementary dsRNA precursors [61,62]. DCL3 produces 24-nt siRNAs (hc-siRNA) that typically silence gene expression via the RdDM pathway [63,64]. These hc-siRNAs are transcribed at the heterochromatic regions where they stimulate cytosine methylation in the sequence contexts of CG, CHG, and CHH, in cis $[65,66]$. The DCL3-dependent miRNAs integrate with AGO4 forming a complex which repress gene silencing by cytosine and histone methylation [67]. However, the de novo hc-siRNA-induced RdDM process integrates the activities of RDR, DCL, AGO, and Pol IV and V which transcribe the double-stranded precursors and promote methylation at the target sites respectively [64]. Therefore, DNA and lysine methylation at the ninth position of histone H3 (H3K9) induces systemic silencing [66], while the hc-siRNA/AGO4 RISC guides DNA and H3K9 methyltransferases to the target sequence for transcriptional gene silencing $[65,66]$.

\subsection{Gene Expression Regulation by $\operatorname{lncRNAs}$}

Long non-coding RNAs are intermediates between ribonucleic acids and proteins. They regulate gene expression as transcriptional activators or repressors [68], though the molecular basis of how they do so is poorly understood in plants. In this section, we only discussed the lncRNAs gene regulation mechanisms, which have been characterized so far to alter transcriptional and post-transcriptional expression levels in plants.

Plant lncRNAs function in cis and trans. The cis-acting lncRNAs function near their synthesis sites and operate directly on the local nucleotide sequences or chromosome regions on one or more contiguous genes. The trans-acting lncRNAs, on the other hand, disperse from the synthesis site and can function on several genes at great distances, including on different chromosomes [69]. Moreover, lncRNAs can also be transcribed as sRNAs precursors [70]. For instance, a subset of lncRNAs can form double-stranded RNA duplexes with Natural Antisense Transcripts (NAT) to produce sRNAs which carry out their regulatory functions. In Arabidopsis, the Rab2-like gene and a pentatricopeptide repeat gene generated a NAT pair from their complementary region with an endogenous siRNA [71]. LncRNAs can serve as miRNA target mimics where the lncRNAs competes with the target mRNA for miRNA binding, thereby blocking the action of the miRNA and relieving repression of its target gene [72]. In Arabidopsis under phosphate deficiency (P) conditions, a lncRNA called Induced by Phosphate Starvation 1 (IPS1) was reported to mimic miRNA399 [73,74]. Moreover, IncRNAs often functions through protein-protein interactions, modification, localization [75-77], and via epigenetic regulation mechanisms such as DNA methylation, histone modification, and chromatin remodeling [78]. Like DNA methylation, IncRNAs have strand-specific distribution and expression patterns, which qualifies them to be ideal regulators of DNA methylation. The COOLAIR and COLDAIR lncRNAs repress the expression of FLOWERING LOCUS C (FLC) via chromatin modification during vernalization [79].

\section{Function of ncRNAs in Response to Abiotic Stress in Plants}

Plants have developed various mechanisms to adjust their growth and development during environmental stress conditions. Multiple research findings have recently shown the differential 
expression of ncRNAs in such unfavourable conditions [80,81]. These ncRNAs either control gene expression in related cellular networks or function directly in response to stress [82]. In this section, we focused on the roles of miRNAs, siRNAs, and lncRNAs on abiotic stress response in plants.

\subsection{Involvement of miRNAs in Abiotic Stress Response}

miRNAs have become new targets for improving plant productivity and abiotic stress tolerance due to the broad functions of their targets [83]. The regulation of miRNAs appears to rely on their roles on the abiotic stress response. Stress-up-regulated miRNAs might down-regulate their target genes, which might be negative regulators of stress tolerance (e.g., stress-responsive gene repressors) [84]. Moreover, the down-regulation of miRNAs under stress might accumulate their target gene mRNAs, which might positively regulate stress tolerance [84]. In this section, we focused on the common significant roles of miRNAs and difficulties encountered to systematically characterize these miRNAs in response to abiotic stress in plants.

The expression of miRNAs is enhanced or suppressed in response to distinct abiotic stress. MiR393, miR397b, and miR402 were up-regulated in Arabidopsis, while miR319c and miR389a were down-regulated under dehydration stress [15]. Similarly, under drought stress in rice at the seedling stage, 17 and 16 miRNAs were suppressed and enhanced, respectively [85]. In maize under drought stress conditions, 8 and 13 miRNAs were up-regulated and down-regulated respectively in the leaves while 7 miRNAs were up-regulated and another 7 down-regulated in the roots [86]. Drought stress, on the other hand, increased the expression of miR156, miR160, miR162, miR164, and miR171, leading to a decrease in the expression of their target genes (Figure 5). miR160 target auxin response factors (ARFs) genes. ARF16 is reportedly involved in the development of root cap cells, while ARF17 acts as a nearly auxin-response gene regulator. Down-regulation of ARF16 and ARF17 will repress plant growth and thereby increase the resistance of maize to drought stress. Likewise, down-regulation of miR169 (Figure 5) led to the accumulation of nuclear factor Y (NFY), which regulates the expression of nitrate transporters, AtNRT2.1 and AtNRT1.1 [87].

Moreover, one miRNA maybe both down-regulated and up-regulated in the same abiotic stress response in one plant. The expression of miR398a/b in the Medicago truncatula was found to be enhanced and repressed in response to drought stress according to different reports [88]. Similarly, miR156, miR164, and miR171 exhibited discrete regulatory trends under drought stress in maize [86], while miR156 and miR171 exhibited contrary regulations patterns in two individual studies of rice under drought stress $[89,90]$. Additionally, contrasting miRNA expression during the same abiotic stress conditions has been reported in two different plant species. The expression of miR159 in maize and Arabidopsis was suppressed in response to drought stress, but enhanced in rice and wheat, while miR399 was up-regulated in maize and wheat, but down-regulated in rice. miR168, miR397, and miR188 were all enhanced in Arabidopsis and suppressed in maize (Figure 6) [86,91,92]. More research is required to explain the discrepancy in the expression of such miRNAs, which might be due to differences in the severity of abiotic stress and/or other plant growth conditions.

Some miRNAs are evolutionarily preserved among plant species in stress adaptation. Several miRNAs such as miR169, miR171, miR395, miR397, miR398, miR399, miR408, and miR827, were all up-regulated in both Arabidopsis and maize in response to nitrogen (N) deficiency [93,94]. Similarly, miR160, miR162, miR395, miR827, were all up-regulated, while miR166, miR172, miR397, miR827, and miR1432 were all down-regulated in maize, Arabidopsis, rice, and wheat in response to drought stress (Figure 6) [86,90-92]. Conservation of these miRNAs suggests they have preserved biological functions, but miR171 exhibited distinct patterns of expression under drought stress in maize and rice $[86,89,90]$. Thus, further research is required to investigate what causes such variations in such comparable situations. 


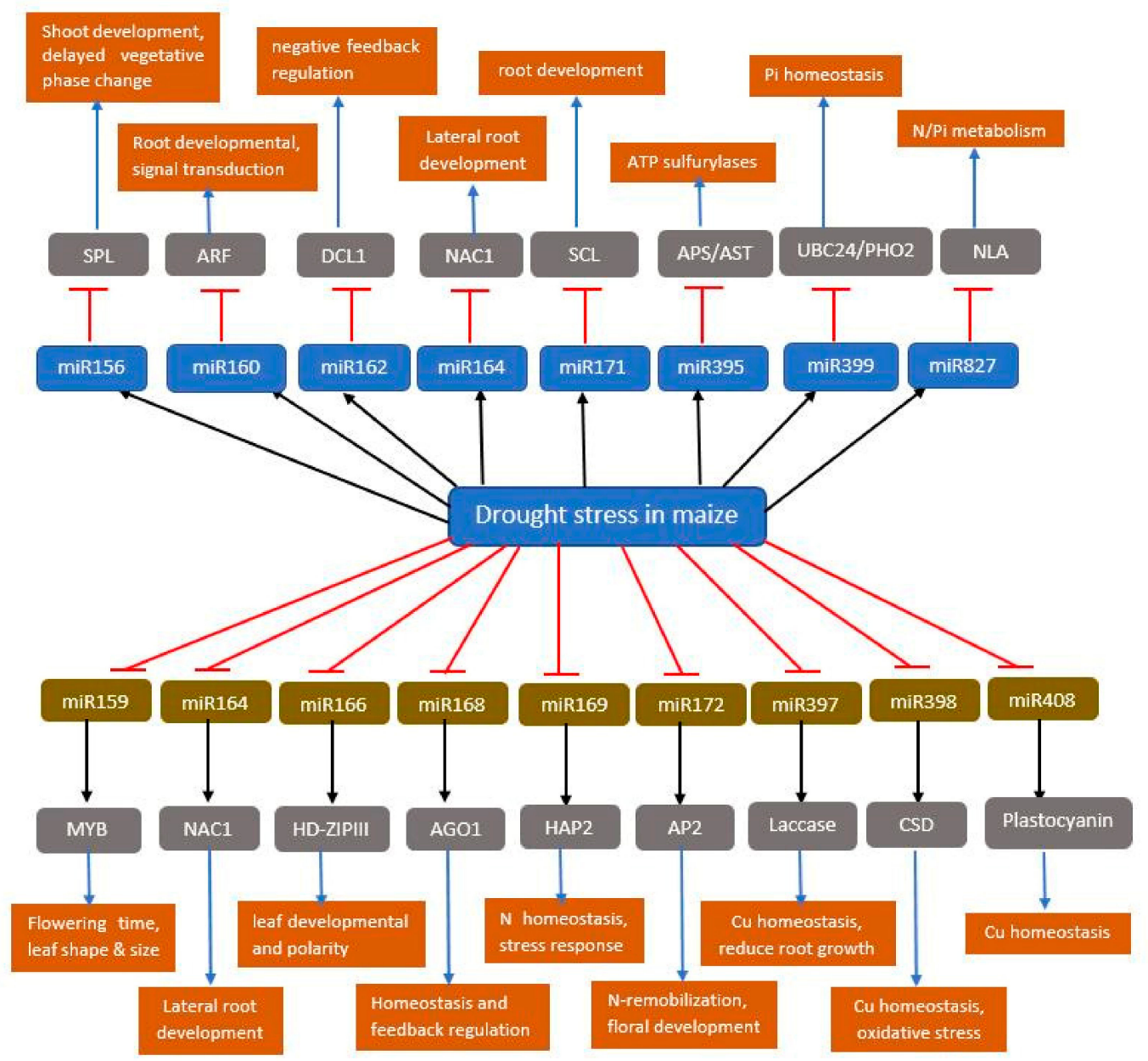

Figure 5. The miRNAs-guided target gene regulations under drought stress in maize. miRNAs that are positively regulated by drought stress (black arrow and blue rectangle) target negative regulators (top gray rectangle) of stress tolerance for enhanced suppression (red blunt arrow) of target gene products. By contrast, miRNAs that are suppressed by drought stress (red blunt arrow and gold rectangle) likely target positive regulators (bottom gray rectangle) of stress tolerance resulting in the accumulation of gene products (orange rectangle) which regulate drought stress response. SPL, sporocyteless; ARF, auxin response factor; DCL1, dicer like protein; NAC1, no apical meristem; SCL, scarecrow-like 3; APS, ATP sulfurylase; UBC24/PHO2, ubiquitin-conjugating Enzyme E2/phosphate 2; NLA, nitrogen limitation adaptation; MYB, myeloblastosis; HD-ZIP III, homeodomain-leucine zipper 3; HAP2, heme activator protein 2; $\mathrm{AP2}$, apetala 2; CSD, copper/zinc superoxide dismutase.

Interestingly, some miRNAs are generally responsive to various abiotic stresses. In Arabidopsis, the expression of miR398 was inhibited by oxidative stress, salt, ABA, and high $\mathrm{Cu}^{2+}$, while miR169a and miR169c were inhibited by drought and ABA stress [95] (Figure 7). In comparison, the expression of miR393 was induced in Arabidopsis by salt, drought, cold, ABA, and UV-B stresses (Figure 7). Also, some miRNAs respond to certain abiotic stresses differently. In Arabidopsis, miR169 was induced by salt, cold, and UVB irradiation but suppressed by drought, heat, and ABA treatment [95]. 


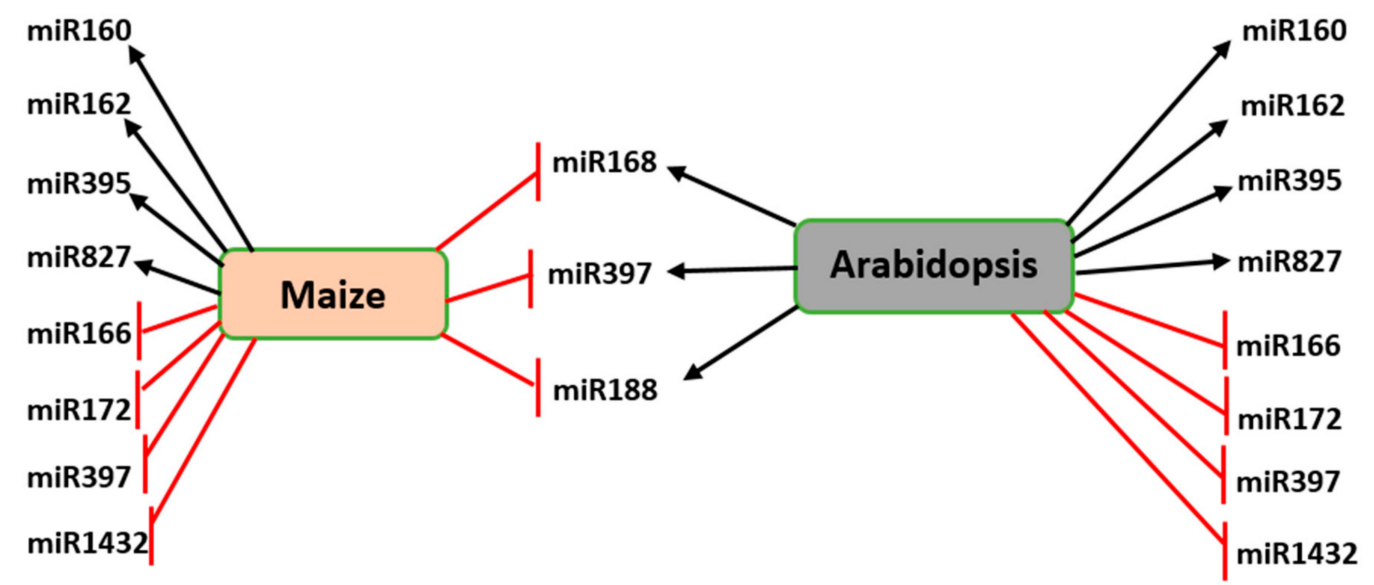

Figure 6. Differential expression of commonly expressed miRNAs in maize and Arabidopsis during the drought stress response. Expression of miR168, miR397, and miR188 is down-regulated in maize but up-regulated in Arabidopsis. A red blunt arrow indicates a decrease while the black arrow represents an increase in the expression of the corresponding miRNA.

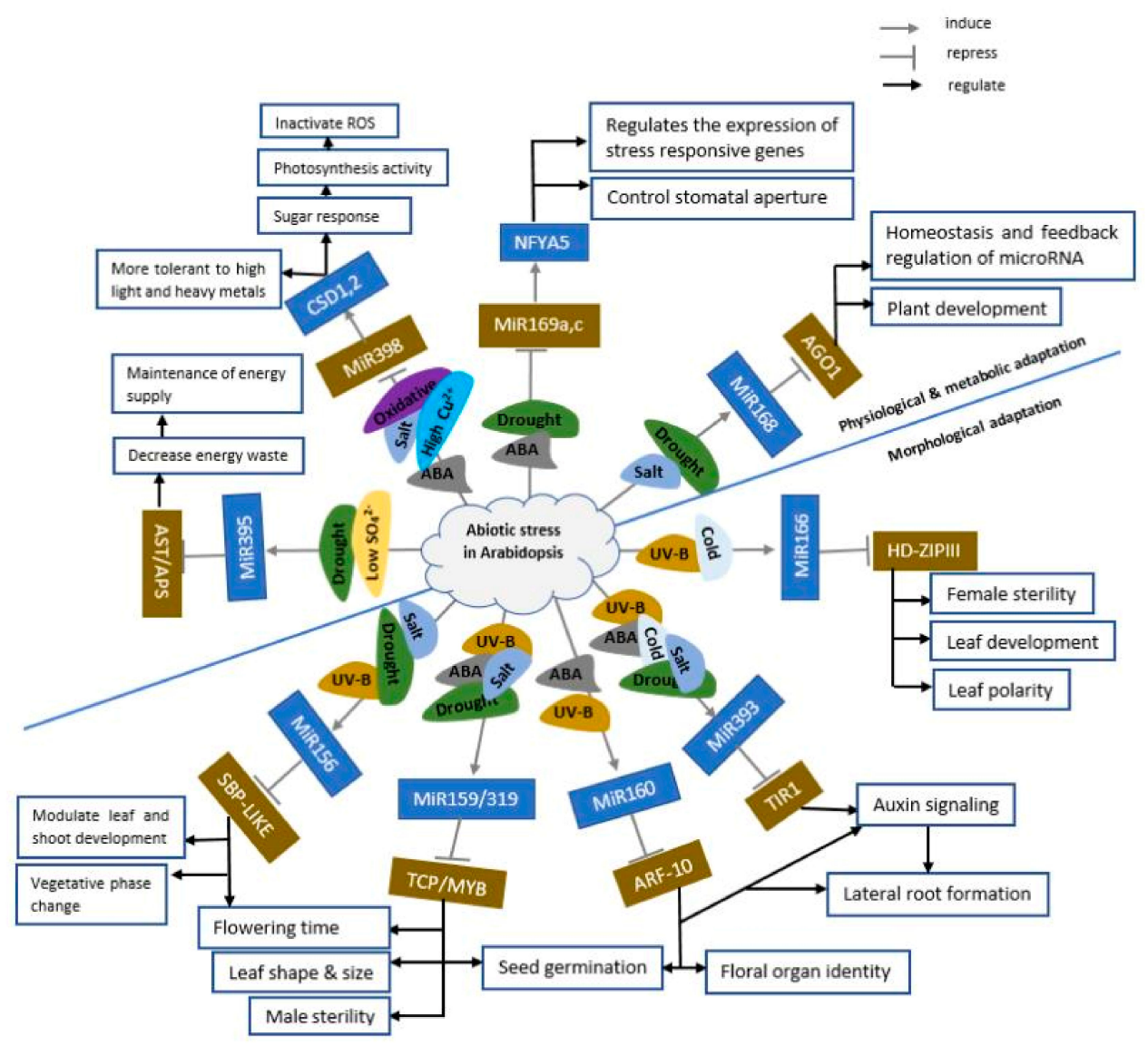

Figure 7. Regulatory network of miRNAs in Arabidopsis under abiotic stress. The proposed network describes the molecular mechanisms underlying the response of Arabidopsis plants to various abiotic stresses. The network is solely based on alterations in miRNA expression patterns and subsequent target transcripts in stressed plants.

Several studies have shown that certain miRNAs display tissue-dependent expression patterns. During drought stress, more miRNAs were expressed in roots than leaves of peach, indicating that root is more susceptible to drought than leaf tissue [96]. In maize, miR166 was down-regulated in leaves and up-regulated in roots under drought stress [86], while in wheat, six miRNAs (miR159, 
miR172, miR319, miR399, miR528, and miR4393) were induced in leaves but inhibited in roots under drought stress conditions [91]. Likewise, four miRNAs (hvu-miR156a, hvu-miR166, hvu-miR171, and hvu-miR408) were induced in barley leaves by drought stress, but hvu-miR166 was suppressed in barley roots while the remaining three were unchanged [97].

The treatment method applied for abiotic stresses in plants also contributes to the variation in the expression patterns of the same miRNAs [88]. For instance, polyethylene glycol (PEG) simulated drought stress differed significantly from the actual field drought [98]. In maize, the expression of miR398 was induced by PEG treatment but down-regulated under natural drought conditions [99,100]. PEG treatment up-regulated miR159 and miR166 in maize leaves while field simulated drought down-regulated both miRNAs [100-102]. Moderate and severe filed drought down-regulated and up-regulated miR156, respectively, while 16 and $24 \mathrm{~h}$ PEG simulated treatment up-regulated and down-regulated miR156, respectively $[99,102]$. Field simulated drought stress up-regulated miR399 in both leaves and roots, but PEG simulated treatment down-regulated expression of miR399 [99]. These findings suggest ambiguity between field and PEG simulated drought on the expression of miRNAs.

\subsection{Roles of siRNAs in Abiotic Stress Response in Plants}

Recently, the involvement of siRNAs in plant abiotic stress responses has been explored [15]. In Arabidopsis, the pairing of the nat-siRNA SRO5 and Pyrroline-5-carboxylate dehydrogenase (P5CDH) regulated proline metabolism, thereby mitigating reactive oxygen species (ROS) induced by high salt stress [34]. The levels of TAS1, TAS2, and TAS3 tasiRNAs were significantly elevated in hypoxia-treated Arabidopsis samples indicating their function in stress response [103,104], (Table 1). These variations in tasiRNA levels have been shown to correlate with the TAS targeting levels of miRNAs (miR173 and miR390) [103]. Pentatricopeptide repeat (PPR) mRNAs are the targets of TAS2, and down-regulation of these targets are associated with the defense of mitochondria during hypoxic [105]. The HEAT-INDUCED TAS1 TARGET1 (HTT1) and HTT2 are TAS1 targets that are normally induced by heat stress conditions in Arabidopsis [106]. Over-expression of TAS1 reduces the HTT gene expression levels, thereby causing weaker thermotolerance, while over-expression of HTT genes up-regulates HSF genes, thereby increasing thermotolerance [107]. Transcription of HTT genes was induced in heat-tolerant transgenic plants over-expressing the HSFA1a gene. This HSFA1a gene was reported to activate the expression of HTT by binding to their promoters [107]. In Arabidopsis, HTT1 was found to interact with HSP70-14 and HSP40. Collectively, these results suggest that HTT1 is a cofactor of HSP70-14 complexes, mediates TAS1a-targeted thermotolerance pathways, and is triggered by HSFA1a [107]]. On the other hand, miR828 regulated ta-siRNAs (TAS4) transcript is critical for the biosynthesis of anthocyanins in response to phosphate deficiency in Arabidopsis [108,109]. The induction of TAS4-siR81(-) led to the accumulation of anthocyanin in nitrogen deficiency conditions [109], (Table 1). TAS4-siR81(-) targets MYB transcripts which are vital for the biosynthesis of anthocyanin.

In a recent study, a copia-type retrotransposon called ONSEN was activated in Arabidopsis seedlings under heat stress conditions [110]. In addition, new ONSEN insertions were observed to occur in stressed plants deficient in siRNA biogenesis via retrotransposition. These insertions were passed on to the next generation, and they conferred heat responsiveness to nearby genes [110-112], (Table 1). Thus, the siRNA-directed pathway plays a significant role in controlling transgenerational retrotransposition triggered by abiotic stress. A research study in Chinese cabbage suggested that several chloroplasts small RNAs (csRNAs) and nat-siRNAs were responsive to heat stress $[113,114]$. Differential expression analysis in Brassica rapa showed that nat-siRNAs derived from 12 cis-NATs were susceptible to heat stress, with the transcripts producing heat-responsive nat-siRNAs being up-regulated while those transcripts from the opposite strands of the same loci being down-regulated under heat stress [114], (Table 1). Similarly, a Craterostigma plantagineum dehydration-related ABA-inducible gene has been reported to direct the synthesis of an endogenous siRNA that plays a role in Craterostigma dehydration tolerance [115]. Northern blot analysis in wheat seedlings indicated that the expression of 
four siRNA changed significantly in response to cold, heat, salt, and dehydration stresses [116], (Table 1). Heat and $\mathrm{NaCl}$ stress suppressed the expression of 002061_0636_3054.1 siRNA and 005047_0654_1904.1 siRNA [116]. The genes targeted by these siRNAs may be significant in regulating multiple stress responses in wheat.

Table 1. Examples of siRNAs associated with Abiotic stress response in plants.

\begin{tabular}{cccc}
\hline siRNA & Abiotic Stresses Regulated & Plant Species & References \\
\hline SRO5-P5CDH nat-siRNA & $\downarrow$ by salt stress & Arabidopsis & {$[34]$} \\
TAS1, TAS2, TAS3 ta-siRNA & $\uparrow$ by hypoxia stress & Arabidopsis & {$[103-105]$} \\
HTT1, HTT2-TAS1 & $\uparrow$ by heat stress & Arabidopsis & {$[106,107]$} \\
TAS4 ta-siRNAs & $\uparrow$ by phosphate deficiency stress & Arabidopsis & {$[108,109]$} \\
TAS4-siR81(-) & $\uparrow$ by nitrogen deficiency stress & Arabidopsis & {$[109]$} \\
hcsiRNAs (ONSEN) & $\uparrow$ by heat stress & Arabidopsis & {$[110-112]$} \\
nat-siRNAs & $\uparrow$ by heat stress & Cabbage & {$[113,114]$} \\
nat-siRNAs & $\uparrow \& \downarrow$ by heat stress & Brassica rapa & {$[114]$} \\
CDT1-siRNA & $\uparrow$ by dehydration stress & Craterostigma & {$[115]$} \\
002061_0636_3054.1 siRNA & $\downarrow$ by heat, NaCl, \& dehydration & Wheat & {$[116]$} \\
005047_0654_1904.1 siRNA & $\downarrow$ by heat, NaCl, \& dehydration & Wheat & {$[116]$} \\
005047_0654_1904.1 siRNA & $\uparrow$ by cold stress & Wheat & {$[116]$} \\
080621_1340_0098.1 siRNA & $\uparrow$ by cold stress but $\downarrow$ by heat stress & Wheat & {$[116]$} \\
007927_0100_2975.1 siRNA & $\downarrow$ by cold, NaCl, and dehydration & Wheat & {$[116]$} \\
hcsiRNAs (HD2C, HDA6) & $\uparrow \& \downarrow$ by drought, ABA stress & Arabidopsis & {$[117-122]$} \\
ta-siRNA TAS3a-5'D6 (+) & $\uparrow$ by cold stress & Wheat & {$[123]$} \\
3 ta-siRNAs & $\uparrow \& \downarrow$ by cold stress & Cassava & {$[124]$} \\
2 nat-siRNA & $\uparrow \& \downarrow$ by cold stress & Cassava & {$[124]$} \\
\hline
\end{tabular}

The symbol $\uparrow$, an upward pointing arrow refers to induced expression while the arrow symbol $\downarrow$, a downwards pointing arrow refers to suppressed expression of siRNAs during corresponding abiotic stress.

In Arabidopsis, transgenerational responses are based on DNA methylation mediated by hcsiRNAs during abiotic stress [117]. Moreover, modification triggered by histone deacetylases 2C (HD2C) and HDA6 contributes to water deficit and ABA responses [118,119]. Loss of HDA6 reactivated transcription of an RdDM target [120], while HDA6 and HD2C interacted with DNA methyltransferase MET1 and AtDNMT2, respectively [121,122]. Collectively, the association between histone deacetylases and DNA methyltransferases indicates that HDA6 and HD2C are part of sncRNA regulatory pathway that is involved in water deficit and ABA responses.

In other studies, ta-siRNA TAS3a-5'D6 (+) was reported to regulate the auxin signaling pathway by guiding the cleavage of ARF, thereby playing a key role in the adaptation of wheat to cold stress [123]. Similarly, three TAS3 derived ta-siRNAs were shown to target cassava ARFs under cold stress conditions [124], (Table 1). Thus, ta-siRNA 's response to cold stress is correlated with auxin signaling in plants. In cassava, two nat-siRNAs were differentially expressed in response to cold stress. One of them encoded the transcriptional regulator of the NAC (No Apical Meristem) domain, which has been involved in plant response to cold [124].

\subsection{Roles of lncRNAs in Plant Abiotic Stress Response}

Recent studies have shown that plant lncRNAs are involved in various abiotic stress responses [80,125]. These lncRNAs have been reported to execute their functions in responding to abiotic stresses in different ways. First, some plant lncRNAs participate in abiotic stress response through target mimicry. They act as competitive endogenous RNAs (ceRNAs) targeted by miRNAs, thereby blocking miRNA interactions with their targets [126]. In Arabidopsis under P deficiency conditions, lncRNA IPS1 was reported to mimic miRNA399, thereby blocking it from interacting with its target PHOSPHATE 2 (PHO2), resulting in weakened miR399- mediated repression of PHO2 [73,74,127], (Table 2). Similar mimicry roles of lncRNAs have been reported in rice under P 
deficiency [128]. In Populus trichocarpa, ptc-miR482a.1, ptc-miR476a, and ptc-miR156c were reported as targets mimicry of drought-responsive lncRNAs [129] (Table 2).

Plant antisense lncRNAs interact with sense mRNAs during abiotic stress response. Such interactions lead to the formation of double-stranded RNA duplexes, thus affecting the expression of the gene on the opposite strand [135]. Five antisense IncRNAs were found in poplar under nitrogen deficiency conditions [131]. Similar findings have also been reported in maize under drought stress [133] and in Arabidopsis under light and heat stress conditions [135,136] (Table 2).

Also, some plant lncRNAs are responsive to abiotic stress through chromatin remodeling [78]. The expression of COOLAIR and COLDAIR represses FLC in cold-stressed Arabidopsis via lncRNA-mediated chromatin modifications (lncR2Epi) [137,138], (Table 2). COOLAIR mediates the reduction of H3K36me3 or H3K4me2 at FLC $[137,138]$ while COLDAIR combines with polycomb repressive complex2 (PRC2) to promote H3K27me3 accumulation at FLC $[137,138]$. In Arabidopsis, the expression of $40-50 \%$ of light-responsive sense/antisense transcripts associated with H3K9ac and/or H3K27ac were significantly regulated under high light stress conditions [135]. Therefore, histone modification and histone acetylation are crucial for the light-responsive expression changes of NATs.

Some lncRNAs respond to environmental stress through the RdDM pathway. In tomatoes, suppression of SIAGO4A, which codes for a core factor of the RdDM pathway, significantly increased resistance of salt and drought stress compared to wild species and transgenic plants over-expressing SlAGO4A [139]. In response to heat stress, the Arabidopsis mutants $r d r 2$ and $d c l 3$ exhibited reduced survival rates [140]. In Arabidopsis, heat stress-induced the expression of a vacuolar protein 4 (Vps4) gene with an enhanced expression of the same gene observed in the $n r p d 2$ mutant [140]. The RdDM pathway regulated an MYB domain protein 74 (MYB74) in Arabidopsis during salt stress conditions [141].

Plant lncRNAs can act as sRNA precursors during abiotic stress response [70]. Nine lincRNAs serving as precursors for 11 known miRNAs were identified in a study of Populus under N deficiency, while another five lincRNAs were precursors for 14 novel miRNAs [130]. In his study, Song et al. [131] reported 9,687 novel lncRNAs and 50 lncRNAs, which acted as miRNA precursors in Brassica rapa under cold and heat stress. Similar results were reported in Phaeodactylum tricornutum under P deficiency conditions [132], (Table 2). In Populus simonii, two IncRNAs, Psi-IncRNA00020674 and Psi-lnc00201294 were suggested to be the precursors of miRNA166a and miRNA27 by overlapping with the genomic regions generating these miRNAs [122]. Several lncRNAs were identified as miRNA, siRNA, and shRNA in Zea mays under drought stress conditions [133], and wheat (Triticum aestivum) under heat stress [116,134], (Table 2). 
Table 2. Examples of lncRNAs associated with abiotic stress response in plants.

\begin{tabular}{|c|c|c|c|}
\hline lncRNAs & Mechanism & Stress Association & References \\
\hline IPS1 & miR399 target mimicry & $\uparrow$ in response to phosphate deficiency (Arabidopsis thaliana) & {$[73,74,127]$} \\
\hline $\operatorname{lncRNAs}$ & target mimicry & $\uparrow \& \downarrow$ in response to phosphate deficiency (Oryza sativa) & [128] \\
\hline lincRNA1128 & ptc-miR482a.1 target mimicry & $\downarrow$ in response to drought stress (Populus trichocarpa) & [129] \\
\hline lincRNA1393 & ptc-miR6459b target mimicry & $\downarrow$ in response to drought stress (Populus trichocarpa) & [129] \\
\hline lincRNA3018 & ptc-miR399i target mimicry & $\downarrow$ in response to drought stress (Populus trichocarpa) & [129] \\
\hline lincRNA2752 & ptc-miR169o target mimicry & $\uparrow$ in response to drought stress (Populus trichocarpa) & [129] \\
\hline lincRNA1795 & ptc-miR476a target mimicry & $\downarrow$ in response to drought stress (Populus trichocarpa) & [129] \\
\hline lincRNA20 & ptc-miR476a target mimicry & $\uparrow$ in response to drought stress (Populus trichocarpa) & [129] \\
\hline lincRNA2623 & ptc-miR156k target mimicry & $\downarrow$ in response to drought stress (Populus trichocarpa) & [129] \\
\hline lincRNA2623 & ptc-miR156c target mimicry & $\downarrow$ in response to drought stress (Populus trichocarpa) & [129] \\
\hline lincRNA967 & ptc-miR6462e target mimicry & | in response to drought stress (Populus trichocarpa) & [129] \\
\hline lincRNA2762 & ptc-miR156k target mimicry & $\downarrow$ in response to drought stress (Populus trichocarpa) & [129] \\
\hline lincRNA1449 & ptc-miR156k target mimicry & | in response to drought stress (Populus trichocarpa) & [129] \\
\hline lincRNA179 & ptc-miR156a target mimicry & in response to drought stress (Populus trichocarpa) & [129] \\
\hline lincRNA2198 & nd & $\uparrow$ in response to drought stress (Populus trichocarpa) & [129] \\
\hline lincRNA2131 & nd & $\uparrow$ in response to drought stress (Populus trichocarpa) & [129] \\
\hline lincRNA2085 & nd & $\uparrow$ in response to drought stress (Populus trichocarpa) & [129] \\
\hline lincRNA2962 & nd & $\uparrow$ in response to drought stress (Populus trichocarpa) & [129] \\
\hline lincRNA1534 & nd & $\uparrow$ in response to drought stress (Populus trichocarpa) & [129] \\
\hline lincRNA1039 & nd & $\uparrow$ in response to drought stress (Populus trichocarpa) & [129] \\
\hline lincRNA2962 & nd & $\downarrow$ in response to drought stress (Populus trichocarpa) & [129] \\
\hline lincRNAs & miRNAs precursors & $\uparrow \& \downarrow$ in response to nitrogen deficiency stress (Populus tomentosa) & [130] \\
\hline lincRNAs & miRNAs precursors & $\uparrow \& \downarrow$ in response to cold and heat stress (Brassica rapa) & [131] \\
\hline pti-MIR5472 & miR5472 precursors & $\uparrow$ in response to phosphate deficiency (Phaeodactylum tricornutum) & [132] \\
\hline pti-MIR5471 & miR5471 precursors & $\uparrow$ in response to phosphate deficiency (Phaeodactylum tricornutum) & [132] \\
\hline lncRNAs & sRNA precursors & $\uparrow$ in response to drought stress (Zea mays) & [133] \\
\hline TalnRNA5 & ta-miR2004 precursors & $\uparrow$ in response to heat stress (Triticum aestivum) & {$[116,134]$} \\
\hline TahlnRNA27 & ta-miR2010 precursors & $\uparrow$ in response to heat stress (Triticum aestivum) & {$[116,134]$} \\
\hline TalnRNA21 & siRNA precursors & $\uparrow$ in response to heat stress (Triticum aestivum) & {$[116,134]$} \\
\hline TahlnRNA3 & siRNA precursors & $\uparrow$ in response to heat stress (Triticum aestivum) & {$[116,134]$} \\
\hline TahlnRNA14 & siRNA precursors & $\uparrow$ in response to heat stress (Triticum aestivum) & {$[116,134]$} \\
\hline TahlnRNA19 & siRNA precursors & $\uparrow$ in response to heat stress (Triticum aestivum) & {$[116,134]$} \\
\hline TahlnRNA36 & siRNA precursors & $\uparrow$ in response to heat stress (Triticum aestivum) & {$[116,134]$} \\
\hline TahlnRNA41 & siRNA precursors & $\uparrow$ in response to heat stress (Triticum aestivum) & {$[116,134]$} \\
\hline
\end{tabular}


Table 2. Cont.

\begin{tabular}{|c|c|c|c|}
\hline lncRNAs & Mechanism & Stress Association & References \\
\hline TahlnRNA42 & siRNA precursors & $\uparrow$ in response to heat stress (Triticum aestivum) & {$[116,134]$} \\
\hline TahlnRNA47 & siRNA precursors & $\uparrow$ in response to heat stress (Triticum aestivum) & {$[116,134]$} \\
\hline TahlnRNA52 & siRNA precursors & $\uparrow$ in response to heat stress (Triticum aestivum) & {$[116,134]$} \\
\hline lincRNAs & antisense transcription & $\uparrow \& \downarrow$ in response to nitrogen deficiency stress (Populus tomentosa) & [130] \\
\hline lncRNAs & antisense transcription & $\uparrow$ in response to drought stress (Zea mays) & [133] \\
\hline lncRNAs & antisense transcription & $\uparrow$ in response to light stress (Arabidopsis thaliana) & [135] \\
\hline asHSFB2a & antisense transcription & $\uparrow$ in response to heat stress (Arabidopsis thaliana) & [136] \\
\hline COOLAIR & chromatin remodeling & $\uparrow$ in response to cold stress (Arabidopsis thaliana) & {$[137]$} \\
\hline lncRNAs & histone modification & $\uparrow$ in response to light stress (Arabidopsis thaliana) & [135] \\
\hline COLDAIR & histone modification & $\uparrow$ in response to cold stress (Arabidopsis thaliana) & [138] \\
\hline lncRNAs & RdDM pathway & $\downarrow$ in response to salt and drought stress (tomatoes) & [139] \\
\hline lncRNAs & RdDM pathway & $\downarrow$ in response to heat stress (Arabidopsis thaliana) & {$[140]$} \\
\hline lncRNAs & RdDM pathway & $\downarrow$ in response to salt stress (Arabidopsis thaliana) & [141] \\
\hline
\end{tabular}
The symbol $\uparrow$, an upward pointing arrow refers to induced expression while the arrow symbol $\downarrow$, a downwards pointing arrow refers to suppressed expression of lncRNAs during
corresponding abiotic stress. Similarly, the symbol |, without any pointing direction refers to non-responsive lncRNAs while nd indicates that the mechanism of that particular lncRNA has not yet been established. 


\section{Conclusions and Future Perspectives}

Advancements in high-throughput sequencing technology have provided a vital understanding of the fundamental roles that ncRNAs perform during abiotic stress response in plants. The complexity of the ncRNA pathways, however, parallels the diverse spectrum of eukaryotic regulatory pathways, and dozens of questions pertaining to ncRNA functions still need to be addressed.

Despite having a common origin and being conserved in different plants, some ncRNAs exhibit discrete expression patterns in responses to the same abiotic stress across plant species. Moreover, some ncRNAs exhibit tissue-specific expression while others are responsive to specific environmental stresses. Such findings suggest that ncRNA expression is regulated at the level of transcription. However, an additional in-depth research is required to unravel how ncRNA expression is regulated at the transcriptional level in response to environmental changes and whether other transcripts and protein-protein interactions involved in the biogenesis of such ncRNAs are themselves tissueand time-specifically expressed.

At a molecular level, ncRNAs are controlled through multiple ways, including transcription and post-transcription. However, how plants synchronize these processes to regulate the buildup of ncRNAs in response to abiotic stress remains poorly studied. Furthermore, plant response to abiotic stresses requires the coordinated action of various pathways. It is poorly understood how ncRNAs coordinate with other pathway networks to regulate different physiological processes during stress conditions.

Plants ncRNAs vary widely from each other, but they communicate in their mechanisms of action. Their coordinated response suggests that at some stage, these distinct molecules are interconnected. Interestingly, during the environmental stress response, they function collectively as well as individually. However, the functions of most ncRNAs are still unclear, and there is a significant gap between the discovery of ncRNA genes and the verification of their functions. The discovery of more ncRNAs will simultaneously provide researchers with the ability to exploit these ncRNAs in favor of generating plants that can survive abiotic stress. If the regulatory breadth of ncRNAs is as anticipated, then these molecules will be instrumental in improving plant yields, quality, and resistance to various environmental stresses.

Author Contributions: Conceptualization, J.L., H.W. and J.K.W.; writing the original draft J.K.W.; revising and editing the manuscript J.L., H.W., C.Z. and J.K.W. All authors have read and agreed to the published version of the manuscript.

Funding: This research was funded by National Key R\&D Program of China, grant number 2018YFD1000702/2018YFD1000700, National Natural Science Foundation of China, grant number 31900452, key research and development program of Xinjiang province, China, grant number 2018B01006-4 and the Agricultural Science and Technology Innovation Program of CAAS, grant number CAAS-ZDRW202009.

Conflicts of Interest: The authors declare that they have no competing interests.

\section{Abbreviations}

$\begin{array}{ll}\text { AGO } & \text { Argonaute protein } \\ \text { DCL } & \text { Dicer-like protein } \\ \text { SE } & \text { Serrate } \\ \text { HUA } & \text { HUA Enhancer } \\ \text { RDRs } & \text { RNA-dependent RNA polymerases } \\ \text { HYL1 } & \text { Hyponastic leaves 1 } \\ \text { ncRNA } & \text { Non-coding RNA } \\ \text { hcsiRNAs } & \text { Heterochromatic siRNAs } \\ \text { miRNA } & \text { MicroRNA } \\ \text { sRNA } & \text { Small RNAs } \\ \text { lncRNA } & \text { Long non-coding RNA }\end{array}$




$\begin{array}{ll}\text { sncRNA } & \text { Small non-coding RNA } \\ \text { siRNA } & \text { Short interfering RNA } \\ \text { tasiRNA } & \text { Trans-acting RNA } \\ \text { RISC } & \text { RNA-induced silencing complex } \\ \text { SGS } & \text { Suppressor of gene silencing } \\ \text { NGS } & \text { Next-generation sequencing } \\ \text { TGS } & \text { Transcriptional gene silencing } \\ \text { PTGS } & \text { Post-transcriptional gene silencing } \\ \text { RdDM } & \text { RNA-directed DNA methylation } \\ \text { ORF } & \text { Open reading frame } \\ \text { PEG } & \text { Polyethylene glycol } \\ \text { UTR } & \text { Untranslated region } \\ \text { FLC } & \text { Flowering Locus C }\end{array}$

\section{References}

1. Hirayama, T.; Shinozaki, K. Research on plant abiotic stress responses in the post genome era: Past, present and future. Plant J. 2010, 61, 1041-1052. [CrossRef]

2. Mittler, R. Abiotic stress, the field environment and stress combination. Trends Plant Sci. 2006, 11, 15-19. [CrossRef]

3. Pauli, A.; Rinn, J.L.; Schier, A.F. Non-coding RNAs as regulators of embryogenesis. Nat. Rev. Genet. 2011, 12, 136-149. [CrossRef]

4. Rai, M.I.; Alam, M.; Lightfoot, D.A.; Gurha, P.; Afzal, A.J. Classification and experimental identification of plant long non-coding RNAs. Genomics 2019, 111, 997-1005. [CrossRef]

5. Ariel, F.; Romero-Barrios, N.; Jégu, T.; Benhamed, M.; Crespi, M. Battles and hijacks: Noncoding transcription in plants. Trends Plant Sci. 2015, 20, 362-371. [CrossRef]

6. Cech, T.R.; Steitz, J.A. The noncoding RNA revolution-trashing old rules to forge new ones. Cell 2014, 157, 77-94. [CrossRef]

7. Peschansky, V.J.; Wahlestedt, C.W.C. Non-coding RNAs as direct and indirect modulators of epigenetic regulation. Epigenetics 2014, 9, 3-12. [CrossRef]

8. Ponjavic, J.; Ponting, C.P.; Lunter, G. Functionality or transcriptional noise? Evidence for selection within long noncoding RNAs. Genome Res. 2007, 17, 556-565. [CrossRef]

9. Eddy, S.R. Non-coding RNA genes and the modern RNA world. Nat. Rev. Genet. 2001, 2, 919-929. [CrossRef]

10. Shimoni, Y.; Friedlander, G.; Hetzroni, G.; Niv, G.; Altuvia, S.; Biham, O.; Margalit, H. Regulation of gene expression by small-noncoding RNAs: A quantitative view. Mol. Syst. Biol. 2007, 3, 138. [CrossRef]

11. Morris, K.V.; Mattick, J.S. The rise of regulatory RNA. Nat. Rev. Genet. 2014, 15, 423-437. [CrossRef]

12. Brosnan, C.A.; Voinnet, O. The long and the short of noncoding RNAs. Curr. Opin. Cell Biol. 2009, 21, 416-425. [CrossRef]

13. D'Ario, M.; Griffiths-Jones, S.; Kim, M. Small RNAs: Big Impact on Plant Development. Trends Plant Sci. 2017, 22, 1056-1068. [CrossRef]

14. Ingram, J.; Bartels, D. The Molecular Basis of Dehydration Tolerance in Plants. Annu. Rev. Plant Biol. 1996, 47, 377-403. [CrossRef]

15. Sunkar, R.; Zhu, J.K. Novel and stress-regulated microRNAs and other small RNAs from Arabidopsis. Plant Cell 2004, 16, 2001-2019. [CrossRef]

16. Campalans, A.; Kondorosi, A.; Crespi, M. Enod40, a short open reading frame-containing mRNA, induces cytoplasmic localization of a nuclear RNA binding protein in Medicago truncatula. Plant Cell 2004, 16, 1047-1059. [CrossRef]

17. Contreras-Cubas, C.; Palomar, M.; Arteaga-Vázquez, M.; Reyes, J.L.; Covarrubias, A.A. Non-coding RNAs in the plant response to abiotic stress. Planta 2012, 236, 943-958. [CrossRef]

18. Allen, E.; Xie, Z.; Gustafson, A.M.; Sung, G.H.; Spatafora, J.W.; Carrington, J.C. Evolution of microRNA genes by inverted duplication of target gene sequences in Arabidopsis thaliana. Nat. Genet. 2004, 36, 1282-1290. [CrossRef]

19. Nozawa, M.; Miura, S.; Nei, M. Origins and evolution of microRNA genes in Drosophila species. Genome Biol. Evol. 2010, 2, 180-189. [CrossRef] [PubMed] 
20. Voinnet, O. Origin, biogenesis, and activity of plant microRNAs. Cell 2009, 136, 669-687. [CrossRef]

21. Piriyapongsa, J.; Jordan, I.K. Dual coding of siRNAs and miRNAs by plant transposable elements. RNA 2008, 14, 814-821. [CrossRef]

22. Jones-Rhoades, M.W.; Bartel, D.P. Computational identification of plant microRNAs and their targets, including a stress-induced miRNA. Mol. Cell 2004, 14, 787-799. [CrossRef]

23. Axtell, M.J.; Meyers, B.C. Revisiting Criteria for Plant MicroRNA Annotation in the Era of Big Data. Plant Cell 2018, 30, 272-284. [CrossRef]

24. Rogers, K.; Chen, X. MicroRNA biogenesis and turnover in plants. In Cold Spring Harbor Symposia on Quantitative Biology; Cold Spring Harbor Laboratory Press: Cold Spring Harbor, NY, USA, 2012; Volume 77, pp. 183-194.

25. Rogers, K.; Chen, X. Biogenesis, turnover, and mode of action of plant microRNAs. Plant Cell 2013, 25, 2383-2399. [CrossRef]

26. Pareek, M.; Yogindran, S.; Mukherjee, S.K.; Rajam, M.V. Plant MicroRNAs: Biogenesis, Functions, and Applications. In Plant Biology and Biotechnology; Springer: New Delhi, India, 2015; pp. 639-661.

27. Kwak, P.B.; Tomari, Y. The N domain of Argonaute drives duplex unwinding during RISC assembly. Nat. Struct. Mol. Biol. 2012, 19, 145. [CrossRef] [PubMed]

28. Gu, S.; Jin, L.; Huang, Y.; Zhang, F.; Kay, M.A. Slicing-independent RISC activation requires the Argonaute PAZ domain. Curr. Biol. 2012, 22, 1536-1542. [CrossRef]

29. Zheng, B.; Wang, Z.; Li, S.; Yu, B.; Liu, J.Y.; Chen, X. Intergenic transcription by RNA polymerase II coordinates Pol IV and Pol V in siRNA-directed transcriptional gene silencing in Arabidopsis. Genes Dev. 2009, 23, 2850-2860. [CrossRef]

30. Jin, H.; Vacic, V.; Girke, T.; Lonardi, S.; Zhu, J.K. Small RNAs and the regulation of cis-natural antisense transcripts in Arabidopsis. BMC Mol. Biol. 2008, 9, 6. [CrossRef]

31. Erdmann, R.M.; Picard, C.L. RNA-directed DNA Methylation. PLoS Genet. 2020, 16, e1009034. [CrossRef]

32. Gasciolli, V.; Mallory, A.C.; Bartel, D.P.; Vaucheret, H. Partially redundant functions of Arabidopsis DICER-like enzymes and a role for DCL4 in producing trans-acting siRNAs. Curr. Biol. 2005, 15, 1494-1500. [CrossRef]

33. Peragine, A.; Yoshikawa, M.; Wu, G.; Albrecht, H.L.; Poethig, R.S. SGS3 and SGS2/SDE1/RDR6 are required for juvenile development and the production of trans-acting siRNAs in Arabidopsis. Genes Dev. 2004, 18, 2368-2379. [CrossRef]

34. Borsani, O.; Zhu, J.; Verslues, P.E.; Sunkar, R.; Zhu, J.K. Endogenous siRNAs derived from a pair of natural cis-antisense transcripts regulate salt tolerance in Arabidopsis. Cell 2005, 123, 1279-1291. [CrossRef]

35. Mallory, A.C.; Vaucheret, H. Functions of microRNAs and related small RNAs in plants. Nat. Genet. 2006, 38, S31-S36. [CrossRef]

36. Zilberman, D.; Cao, X.; Johansen, L.K.; Xie, Z.; Carrington, J.C.; Jacobsen, S.E. Role of Arabidopsis ARGONAUTE4 in RNA-directed DNA methylation triggered by inverted repeats. Curr. Biol. 2004, 14, 1214-1220. [CrossRef]

37. Kapranov, P.; Cheng, J.; Dike, S.; Nix, D.A.; Duttagupta, R.; Willingham, A.T.; Bell, I. RNA maps reveal new RNA classes and a possible function for pervasive transcription. Science 2007, 316, 1484-1488. [CrossRef]

38. Nie, L.; Wu, H.-J.; Hsu, J.-M.; Chang, S.-S.; Labaff, A.M.; Li, C.-W.; Wang, Y.; Hsu, J.L.; Hung, M.-C. Long non-coding RNAs: Versatile master regulators of gene expression and crucial players in cancer. Am. J. Transl. Res. 2012, 4, 127-150. [PubMed]

39. Nam, J.W.; Bartel, D.P. Long noncoding RNAs in C. elegans. Genome Res. 2012, 22, 2529-2540. [CrossRef]

40. Derrien, T.; Johnson, R.; Bussotti, G.; Tanzer, A.; Djebali, S.; Tilgner, H.; Guernec, G.; Martin, D.; Merkel, A.; Knowles, D.G.; et al. The GENCODE v7 catalog of human long noncoding RNAs: Analysis of their gene structure, evolution, and expression. Genome Res. 2012, 22, 1775-1789. [CrossRef]

41. Bartel, D.P. Micro RNAs: Genomics, biogenesis, mechanism and function. Cell 2004, 116, 281-297. [CrossRef]

42. Bond, D.M.; Baulcombe, D.C. Epigenetic transitions leading to heritable, RNA-mediated de novo silencing in Arabidopsis thaliana. Proc. Natl. Acad. Sci. USA 2015, 112, 917-922. [CrossRef]

43. Hamilton, A.; Voinnet, O.; Chappell, L.; Baulcombe, D. Two classes of short interfering RNA in RNA silencing. EMBO J. 2015, 34, 4671-4679. [CrossRef]

44. Komiya, R.; Ohyanagi, H.; Niihama, M.; Watanabe, T.; Nakano, M.; Kurata, N.; Nonomura, K.I. Rice germline-specific argonaute MEL1 protein binds to phasiRNAs generated from more than 700 lincRNAs. Plant J. 2014, 78, 385-397. [CrossRef] [PubMed] 
45. Rhoades, M.W.; Reinhart, B.J.; Lim, L.P.; Burge, C.B.; Bartel, B.; Bartel, D.P. Prediction of plant microRNA targets. Cell 2002, 110, 513-520. [CrossRef]

46. Lelandais-Brière, C.; Sorin, C.; Declerck, M.; Benslimane, A.; Crespi, M.; Hartmann, C. Small RNA diversity in plants and its impact in development. Curr. Genom. 2010, 11, 14-23. [CrossRef]

47. Liu, T.; Zhang, L.; Chen, G.; Shi, T. Identifying and Characterizing the Circular RNAs during the Lifespan of Arabidopsis Leaves. Front. Plant Sci. 2017, 8, 1278. [CrossRef]

48. Ren, G.; Xie, M.; Zhang, S.; Vinovskis, C.; Chen, X.; Yu, B. Methylation protects microRNAs from an AGO1-associated activity that uridylates 5' RNA fragments generated by AGO1 cleavage. Proc. Natl. Acad. Sci. USA 2014, 111, 6365-6370. [CrossRef]

49. Souret, F.F.; Kastenmayer, J.P.; Green, P.J. AtXRN4 degrades mRNA in Arabidopsis and its substrates include selected miRNA targets. Mol. Cell 2004, 15, 173-183. [CrossRef]

50. Zhu, H.; Hu, F.; Wang, R.; Zhou, X.; Sze, S.-H.; Liou, L.W.; Barefoot, A.; Dickman, M.; Zhang, X. Arabidopsis Argonaute10 specifically sequesters miR166/165 to regulate shoot apical meristem development. Cell 2011, 145, 242-256. [CrossRef]

51. Maunoury, N.; Vaucheret, H. AGO1 and AGO2 act redundantly in miR408-mediated Plantacyanin regulation. PLOS ONE 2011, 6, e28729. [CrossRef]

52. Beauclair, L.; Yu, A.; Bouché, N. microRNA-directed cleavage and translational repression of the copper chaperone for superoxide dismutase mRNA in Arabidopsis. Plant J. 2010, 62, 454-462. [CrossRef]

53. Brodersen, P.; Sakvarelidze-Achard, L.; Bruun-Rasmussen, M.; Dunoyer, P.; Yamamoto, Y.Y.; Sieburth, L.; Voinnet, O. Widespread translational inhibition by plant miRNAs and siRNAs. Science 2008, 320, 1185-1190. [CrossRef]

54. Aukerman, M.J.; Sakai, H. Regulation of flowering time and floral organ identity by a MicroRNA and its APETALA2-like target genes. Plant Cell 2003, 15, 2730-2741. [CrossRef]

55. Cuellar, T.L.; McManus, M.T. MicroRNAs and endocrine biology. J. Endocrinol. 2005, 187, 327-332. [CrossRef]

56. Kim, V.N. Small RNAs: Classification, biogenesis, and function. Mol. Cells 2005, 19, 1-15.

57. Iwakawa, H.O.; Tomari, Y. Molecular insights into microRNA mediated translational repression in plants. Mol. Cell 2013, 52, 591-601. [CrossRef] [PubMed]

58. Li, S.; Liu, L.; Zhuang, X.; Yu, Y.; Liu, X.; Cui, X.; Ji, L.; Pan, Z.; Cao, X.; Mo, B.; et al. MicroRNAs inhibit the translation of target mRNAs on the endoplasmic reticulum in Arabidopsis. Cell 2013, 153, 562-574. [CrossRef]

59. Yang, L.; Wu, G.; Poethig, R.S. Mutations in the GW-repeat protein SUO reveal a developmental function for microRNA-mediated translational repression in Arabidopsis. Proc. Natl. Acad. Sci. USA 2012, 109, 315-320. [CrossRef] [PubMed]

60. Denli, A.M.; Hannon, G.J. RNAi: An ever-growing puzzle. Trends Biochem. Sci. 2003, 28, 196-201. [CrossRef]

61. Bouché, N.; Lauressergues, D.; Gasciolli, V.; Vaucheret, H. An antagonistic function for Arabidopsis DCL2 in development and a new function for DCL4 in generating viral siRNAs. EMBO J. 2006, 25, 3347-3356. [CrossRef]

62. Xie, Z.; Allen, E.; Wilken, A.; Carrington, J.C. DICER-LIKE 4 functions in trans-acting small interfering RNA biogenesis and vegetative phase change in Arabidopsis thaliana. Proc. Natl. Acad. Sci. USA 2005, 102, 12984-12989. [CrossRef]

63. Creasey, K.M.; Zhai, J.; Borges, F.; Van Ex, F.; Regulski, M.; Meyers, B.C.; Martienssen, R.A. miRNAs trigger widespread epigenetically activated siRNAs from transposons in Arabidopsis. Nature 2014, 508, 411-415. [CrossRef]

64. Matzke, M.; Kanno, T.; Daxinger, L.; Huettel, B.; Matzke, A.J. RNA-mediated chromatin-based silencing in plants. Curr. Opin. Cell Biol. 2009, 21, 367-376. [CrossRef]

65. Xie, Z.; Johansen, L.K.; Gustafson, A.M.; Kasschau, K.D.; Lellis, A.D.; Zilberman, D.; Jacobsen, S.E.; Carrington, J.C. Genetic and functional diversification of small RNA pathways in plants. PLoS Biol. 2004, 2, E104. [CrossRef] [PubMed]

66. Zilberman, D.; Cao, X.; Jacobsen, S.E. ARGONAUTE4 control of locus-specific siRNA accumulation and DNA and histone methylation. Science 2003, 299, 716-719. [CrossRef]

67. Ye, R.; Wang, W.; Iki, T.; Liu, C.; Wu, Y.; Ishikawa, M.; Qi, Y. Cytoplasmic assembly and selective nuclear import of Arabidopsis Argonaute4/siRNA complexes. Mol. Cell 2012, 46, 859-870. [CrossRef] 
68. Goodrich, J.A.; Kugel, J.F. Non-coding-RNA regulators of RNA polymerase II transcription. Nat. Rev. Mol. Cell Biol. 2006, 7, 612-616. [CrossRef] [PubMed]

69. Lee, J.T. Epigenetic regulation by long noncoding RNAs. Science 2012, 338, 1435-1439. [CrossRef]

70. Lauressergues, D.; Couzigou, J.M.; San Clemente, H.; Martinez, Y.; Dunand, C.; Bécard, G.; Combier, J.P. Primary transcripts of microRNAs encode regulatory peptides. Nature 2015, 520, 90-93. [CrossRef]

71. Katiyar-Agarwal, S.; Morgan, R.; Dahlbeck, D.; Borsani, O.; Villegas, A.; Zhu, J.-K.; Staskawicz, B.J.; Jin, H. A pathogen-inducible endogenous siRNA in plant immunity. Proc. Natl. Acad. Sci. USA 2006, 103, 18002-18007. [CrossRef] [PubMed]

72. Liu, J.; Wang, H.; Chua, N.H. Long non coding RNA transcriptome of plants. Plant Biotechnol. J. 2015, 13, 319-328. [CrossRef]

73. Aung, K.; Lin, S.I.; Wu, C.C.; Huang, Y.T.; Su, C.L.; Chiou, T.J. pho2, a phosphate over accumulator, is caused by a nonsense mutation in a microRNA399 target gene. Plant Physiol. 2006, 141, 1000-1011. [CrossRef]

74. Franco-Zorrilla, J.M.; Valli, A.; Todesco, M.; Mateos, I.; Puga, M.I.; Rubio-Somoza, I.; Leyva, A.; Weigel, D.; García, J.A.; Paz-Ares, J. Target mimicry provides a new mechanism for regulation of microRNA activity. Nat. Genet. 2007, 39, 1033-1037. [CrossRef]

75. Audas, T.E.; Jacob, M.D.; Lee, S. Immobilization of proteins in the nucleolus by ribosomal intergenic spacer noncoding RNA. Mol. Cell 2012, 45, 147-157. [CrossRef]

76. Wang, P.X.Y.; Han, Y.; Lin, L.; Wu, C.; Xu, S.; Jiang, Z.; Xu, J.; Liu, Q.; Cao, X. The STAT3-binding long noncoding RNA lncSTAT3-binding long noncoding RNA lncDC controls human dendritic cell differentiation. Science 2014, 344, 310-313. [CrossRef]

77. Yang, L.; Froberg, J.E.; Lee, J.T. Long noncoding RNAs: Fresh perspectives into the RNA world. Trends Biochem. Sci. 2014, 39, 35-43. [CrossRef]

78. Matzke, M.A.; Mosher, R.A. RNA-directed DNA methylation: An epigenetic pathway of increasing complexity. Nature Reviews Genetics 2014, 15, 394-408. [CrossRef]

79. Kim, D.H.; Xi, Y.; Sung, S. Modular function of long noncoding RNA, COLDAIR, in the vernalization response. PLoS Genet. 2017, 13, e1006939. [CrossRef]

80. Jha, U.C.; Nayyar, H.; Jha, R.; Khurshid, M.; Zhou, M.; Mantri, N.; Siddique, K.H. Long non-coding RNAs: Emerging players regulating plant abiotic stress response and adaptation. BMC Plant Biol. 2020, 20, 1-20. [CrossRef]

81. Vakilian, K.A. Machine learning improves our knowledge about miRNA functions towards plant abiotic stresses. Sci. Rep. 2020, 10, 1-10.

82. Helliwell, C.A.; Robertson, M.; Finnegan, E.J.; Buzas, D.M.; Dennis, E.S. Vernalization-repression of Arabidopsis FLC requires promoter sequences but not antisense transcripts. PLoS ONE 2011, 6, e2151. [CrossRef]

83. Pandita, D. Plant MIRnome: miRNA Biogenesis and Abiotic Stress Response. In Plant Abiotic Stress Response; Springer: Berlin/Heidelberg, Germany, 2019; pp. 449-474.

84. Sunkar, R.; Chinnusamy, V.; Zhu, J.; Zhu, J.K. Small RNAs as big players in plant abiotic stress responses and nutrient deprivation. Trends Plant Sci. 2007, 12, 301-309. [CrossRef]

85. Zhang, F.; Luo, X.; Zhou, Y.; Xie, J. Genome-wide identification of conserved microRNA and their response to drought stress in Dongxiang wild rice (Oryza rufipogon Griff.). Biotechnol. Lett. 2016, 38, 711-721. [CrossRef]

86. Liu, X.; Zhang, X.; Sun, B.; Hao, L.; Liu, C.; Zhang, D.; Tang, H.; Li, C.; Li, Y.; Shi, Y.; et al. Genome-wide identification and comparative analysis of drought-related microRNAs in two maize inbred lines with contrasting drought tolerance by deep sequencing. PLoS ONE. 2019, 14, e0219176. [CrossRef]

87. Zhao, M.; Ding, H.; Zhu, J.K.; Zhang, F.; Li, W.X. Involvement of miR169 in the nitrogen-starvation responses in Arabidopsis. New Phytol. 2011, 190, 906-915. [CrossRef]

88. Ferdous, J.; Hussain, S.S.; Shi, B.J. Role of microRNAs in plant drought tolerance. Plant Biotechnol. J. 2015, 13, 293-305. [CrossRef]

89. Cheah, B.H.; Nadarajah, K.; Divate, M.D.; Wickneswari, R. Identification of four functionally important micro-RNA families with contrasting differential expression profiles between drought-tolerant and susceptible rice leaf at vegetative stage. BMC Genom. 2015, 16, 692. [CrossRef]

90. Zhou, L.; Liu, Y.; Liu, Z.; Kong, D.; Duan, M.; Luo, L. Genome-wide identification and analysis of drought responsive microRNAs in Oryza sativa. J. Exp. Bot. 2010, 61, 4157-4168. [CrossRef] 
91. Akdogan, G.; Tufekci, E.D.; Uranbey, S.; Unver, T. miRNA-based drought regulation in wheat. Funct. Integr. Genom. 2016, 16, 221-233. [CrossRef]

92. Liu, H.H.; Tian, X.; Li, Y.J.; Wu, C.A.; Zheng, C.C. Microarray-based analysis of stress-regulated microRNAs in Arabidopsis thaliana. RNA 2008, 14, 836-843. [CrossRef]

93. Nguyen, G.; Rothstein, S.; Spangenberg, G.; Kant, S. Role of microRNAs involved in plant response to nitrogen and phosphorous limiting conditions. Front. Plant Sci. 2015, 6, 629. [CrossRef]

94. Zhao, Y.; Xu, Z.; Mo, Q.; Zou, C.; Li, W.; Xu, Y.; Xie, C. Combined small RNA and degradome sequencing reveals novel miRNAs and their targets in response to low nitrate availability in maize. Ann. Bot. 2013, 112, 633-642. [CrossRef]

95. Sunkar, R.; Li, Y.F.; Jagadeeswaran, G. Functions of microRNAs in plant stress responses. Trends Plant Sci. 2012, 17, 196-203. [CrossRef]

96. Eldem, V.; Akcay, U.C.; Ozhuner, E.; Bakır, Y.; Uranbey, S.; Unver, T. Genome-wide identification of miRNAs responsive to drought in peach (Prunus persica) by high-throughput deep sequencing. PLoS ONE 2012, 7, e50298. [CrossRef]

97. Kantar, M.; Unver, T.; Budak, H. Regulation of barley miRNAs upon dehydration stress correlated with target gene expression. Funct. Integr. Genom. 2010, 10, 493-507. [CrossRef]

98. Blum, A. Genomics for drought resistance-Getting down to earth. Funct. Plant Biol. 2014, 11, 1191-1198. [CrossRef]

99. Li, J.S.; Fu, F.L.; Ming, A.N.; Zhou, S.F.; She, Y.H.; Li, W.C. Differential expression of microRNAs in response to drought stress in maize. J. Integr. Agri. 2013, 12, 1414-1422. [CrossRef]

100. Wei, L.; Zhang, D.; Xiang, F.; Zhang, Z. Differentially expressed miRNAs potentially involved in the regulation of defense mechanism to drought stress in maize seedlings. Int. J. Plant Sci. 2009, 170, 979-989. [CrossRef]

101. Aravind, J.; Rinku, S.; Pooja, B.; Shikha, M.; Kaliyugam, S.; Mallikarjuna, M.G.; Kumar, A.; Rao, A.R.; Nepolean, T. Identification, Characterization, and Functional Validation of Drought-responsive MicroRNAs in Subtropical Maize Inbreds. Front. Plant Sci. 2017, 8, 941. [CrossRef]

102. Wang, Y.G.; An, M.; Zhou, S.F.; She, Y.H.; Li, W.C.; Fu, F.L. Expression profile of maize microRNAs corresponding to their target genes under drought stress. Biochem. Genet. 2014, 52, 474-493. [CrossRef]

103. Allen, E.; Xie, Z.; Gustafson, A.M.; Carrington, J.C. microRNA-directed phasing during trans-acting siRNA biogenesis in plants. Cell 2005, 121, 207-221. [CrossRef] [PubMed]

104. Rajagopalan, R.; Vaucheret, H.; Trejo, J.; Bartel, D.P. A diverse and evolutionarily fluid set of microRNAs in Arabidopsis thaliana. Genes Dev. 2006, 20, 3407-3425. [CrossRef]

105. Lurin, C.; Andrés, C.; Aubourg, S.; Bellaoui, M.; Bitton, F.; Bruyère, C.; Caboche, M.; Debast, C.; Gualberto, J.; Hoffmann, B.; et al. Genome-wide analysis of Arabidopsis pentatricopeptide repeat proteins reveals their essential role in organelle biogenesis. Plant Cell 2004, 16, 2089-2103. [CrossRef] [PubMed]

106. Kume, K.; Tsutsumi, K.I.; Saitoh, Y. TAS1 trans-acting siRNA targets are differentially regulated at low temperature, and TAS1 trans-acting siRNA mediates temperature At1g51670 expression. Biosci. Biotechnol. Biochem. 2010, 74, 1435-1440. [CrossRef]

107. Li, S.; Liu, J.; Liu, Z.; Li, X.; Wu, F.; He, Y. Heat-induced tas1 target1 mediates thermotolerance via heat stress transcription factor a1a-directed pathways in Arabidopsis. Plant Cell 2014, 26, 1764-1780. [CrossRef]

108. Hsieh, L.-C.; Lin, S.-I.; Shih, A.C.-C.; Chen, J.-W.; Lin, W.-Y.; Tseng, C.-Y.; Li, W.-H.; Chiou, T.-J. Uncovering small RNA-mediated responses to phosphate deficiency in Arabidopsis by deep sequencing. Plant Physiol. 2009, 151, 2120-2132. [CrossRef]

109. Luo, Q.J.; Mittal, A.; Jia, F.; Rock, C.D. An autoregulatory feedback loop involving PAP1 and TAS4 in response to sugars in Arabidopsis. Plant Mol. Biol. 2012, 80, 117-129. [CrossRef]

110. Ito, H.; Gaubert, H.; Bucher, E.; Mirouze, M.; Vaillant, I.; Paszkowski, J. An siRNA pathway prevents transgenerational retrotransposition in plants subjected to stress. Nature 2011, 472, 115-119. [CrossRef] [PubMed]

111. Matsunaga, W.; Kobayashi, A.; Kato, A.; Ito, H. The effects of heat induction and the siRNA biogenesis pathway on the transgenerational transposition of ONSEN, a copia-like retrotransposon in Arabidopsis thaliana. Plant Cell Physiol. 2012, 53, 824-833. [CrossRef]

112. Stief, A.; Brzezinka, K.; Lämke, J.; Bäurle, I. Epigenetic responses to heat stress at different time scales and the involvement of small RNAs. Plant Signal. Behave. 2014, 9, e970430. [CrossRef] 
113. Wang, L.; Yu, X.; Wang, H.; Lu, Y.Z.; de Ruiter, M.; Prins, M.; He, Y.K. A novel class of heat-responsive small RNAs derived from the chloroplast genome of Chinese cabbage (Brassica rapa). BMC Genom. 2011, 12, 289. [CrossRef] [PubMed]

114. Yu, X.; Yang, J.; Li, X.; Liu, X.; Sun, C.; Wu, F.; He, Y. Global analysis of cis-natural antisense transcripts and their heat-responsive nat-siRNAs in Brassica rapa. BMC Plant Biol. 2013, 13, 208. [CrossRef] [PubMed]

115. Furini, A.; Koncz, C.; Salamini, F.; Bartels, D. High level transcription of a member of a repeated gene family confers dehydration tolerance to callus tissue of Craterostigma plantagineum. EMBO J. 1997, 16, 3599-3608. [CrossRef]

116. Yao, Y.; Ni, Z.; Peng, H.; Sun, F.; Xin, M.; Sunkar, R.; Zhu, J.-K.; Sun, Q. Non-coding small RNAs responsive to abiotic stress in wheat (Triticum aestivum L.). Funct. Integr. Genom. 2010, 10, 187-190. [CrossRef]

117. Boyko, A.; Kovalchuk, I. Transgenerational response to stress in Arabidopsis thaliana. Plant Signal. Behav. 2010, 5, 995-998. [CrossRef]

118. Chen, M.; Lv, S.; Meng, Y. Epigenetic performers in plants. Dev. Growth Differ. 2010, 52, 555-566. [CrossRef]

119. Sridha, S.; Wu, K. Identification of AtHD2C as a novel regulator of abscisic responses in Arabidopsis. Plant J. 2006, 46, 124-133. [CrossRef]

120. Aufsatz, W.; Mette, M.; van der Winden, J.; Matzke, M.; Matzke, A.J. HDA6, a putative histone deacetylase needed to enhance DNA methylation induced by double-stranded RNA. EMBO J. 2002, 21, 6832-6841. [CrossRef]

121. To, T.K.; Kim, J.-M.; Matsui, A.; Kurihara, Y.; Morosawa, T.; Ishida, J.; Tanaka, M.; Endo, T.; Kakutani, T.; Toyoda, T.; et al. Arabidopsis HDA6 regulates locus-directed heterochromatin silencing in cooperation with MET1. PLoS Genet. 2011, 7, e1002055. [CrossRef]

122. Song, Y.; Wu, K.; Dhaubhadel, S.; An, L.; Tian, L. Arabidopsis DNA methyltransferase AtDNMT2 associates with histone deacetylase AtHD2s activity. Biochem. Biophys. Res. Commun. 2010, 396, 187-192. [CrossRef]

123. Tang, Z.; Zhang, L.; Xu, C.; Yuan, S.; Zhang, F.; Zheng, Y.; Zhao, C. Uncovering small RNA-mediated responses to cold stress in a wheat thermosensitive genic male-sterile line by deep sequencing. Plant Physiol. 2012, 159, 721-738. [CrossRef]

124. Xia, J.; Zeng, C.; Chen, Z.; Zhang, K.; Chen, X.; Zhou, Y.; Song, S.; Lu, C.; Yang, R.; Yang, Z.; et al. Endogenous small-noncoding RNAs and their roles in chilling response and stress acclimation in Cassava. BMC Genom. 2014, 15, 634. [CrossRef]

125. Xuan, H.; Zhang, L.; Liu, X.; Han, G.; Li, J.; Li, X.; Zhang, S. PLNlncRbase: A resource for experimentally identified lncRNAs in plants. Gene 2015, 573, 328-332. [CrossRef]

126. Wang, J.; Meng, X.; Dobrovolskaya, O.B.; Orlov, Y.L.; Chen, M. Non-coding RNAs and Their Roles in Stress Response in Plants. Genom. Proteom. Bioinform. 2017, 15, 301-312. [CrossRef]

127. Wu, H.J.; Wang, Z.M.; Wang, M.; Wang, X.J. Widespread long noncoding RNAs as endogenous target mimics for microRNAs in plants. Plant Physiol. 2013, 161, 1875-1884. [CrossRef]

128. Xu, X.W.; Zhou, X.H.; Wang, R.R.; Peng, W.L.; An, Y.; Chen, L.L. Functional analysis of long intergenic non-coding RNAs in phosphate-starved rice using competing endogenous RNA network. Sci. Rep. 2016, 6, 1-12. [CrossRef]

129. Shuai, P.; Liang, D.; Tang, S.; Zhang, Z.; Ye, C.-Y.; Su, Y.; Xia, X.; Yin, W. Genome-wide identification and functional prediction of novel and drought-responsive lincRNAs in Populus trichocarpa. J. Exp. Bot. 2014, 65, 4975-4983. [CrossRef]

130. Chen, M.; Wang, C.; Bao, H.; Chen, H.; Wang, Y. Genome-wide identification and characterization of novel lncRNAs in Populus under nitrogen deficiency. Mol. Genet. Genom. 2016, 291, 1663-1680. [CrossRef]

131. Song, X.; Liu, G.; Huang, Z.; Duan, W.; Tan, H.; Li, Y.; Hou, X. Temperature expression patterns of genes and their coexpression with LncRNAs revealed by RNA-Seq in non-heading Chinese cabbage. BMC Genom. 2016, 17, 297. [CrossRef]

132. Cruz de Carvalho, M.H.; Sun, H.X.; Bowler, C.; Chua, N.H. Noncoding and coding transcriptome responses of a marine diatom to phosphate fluctuations. New Phytol. 2016, 210, 497-510. [CrossRef]

133. Zhang, W.; Han, Z.; Guo, Q.; Liu, Y.; Zheng, Y.; Wu, F.; Jin, W. Identification of maize long non-coding RNAs responsive to drought stress. PLoS ONE 2014, 9, e98958. [CrossRef]

134. Xin, M.; Wang, Y.; Yao, Y.; Song, N.; Hu, Z.; Qin, D.; Xie, C.; Peng, H.; Ni, Z.; Sun, Q. Identification and characterization of wheat long non-protein coding RNAs responsive to powdery mildew infection and heat stress by using microarray analysis and SBS sequencing. BMC Plant Biol. 2011, 11, 61. [CrossRef] 
135. Wang, H.; Chung, P.J.; Liu, J.; Jang, I.C.; Kean, M.J.; Xu, J.; Chua, N.H. Genome-wide identification of long noncoding natural antisense transcripts and their responses to light in Arabidopsis. Genome Res. 2014, 24, 444-453. [CrossRef]

136. Wunderlich, M.; Groß-Hardt, R.; Schöffl, F. Heat shock factor HSFB2a involved in gametophyte development of Arabidopsis thaliana and its expression is controlled by a heat-inducible long non-coding antisense RNA. Plant Mol. Biol. 2014, 85, 541-550. [CrossRef]

137. Csorba, T.; Questa, J.I.; Sun, Q.; Dean, C. Antisense COOLAIR mediates the coordinated switching of chromatin states at FLC during vernalization. Proc. Natl. Acad. Sci. USA 2014, 111, 16160-16165. [CrossRef]

138. Heo, J.B.; Sung, S. Vernalization-mediated epigenetic silencing by a long intronic noncoding RNA. Science 2011, 331, 76-79. [CrossRef] [PubMed]

139. Huang, W.; Xian, Z.; Hu, G.; Li, Z. SLAGO4A, a core factor of RNA-directed DNA methylation (RdDM) pathway, plays an important role under salt and drought stress in tomato. Mol. Breed. 2016, 36, 28. [CrossRef]

140. Popova, O.V.; Dinh, H.Q.; Aufsatz, W.; Jonak, C. The RdDM pathway is required for basal heat tolerance in Arabidopsis. Mol. Plant 2013, 6, 396-410. [CrossRef]

141. Xu, R.; Wang, Y.; Zheng, H.; Lu, W.; Wu, C.; Huang, J.; Yan, K.; Yang, G.; Zheng, C. Salt induced transcription factor MYB74 is regulated by the RNA directed DNA methylation pathway in Arabidopsis. J. Exp. Bot. 2015, 66, 5997-6008. [CrossRef]

Publisher's Note: MDPI stays neutral with regard to jurisdictional claims in published maps and institutional affiliations.

(C) 2020 by the authors. Licensee MDPI, Basel, Switzerland. This article is an open access article distributed under the terms and conditions of the Creative Commons Attribution (CC BY) license (http://creativecommons.org/licenses/by/4.0/). 